\title{
Motivos paganos en mosaicos cristianos y judíos de Oriente: problemática e interpretación (III) ${ }^{1}$
}

\author{
PAu Figueras ${ }^{1 *}$
}

\section{EL MUNDO ASTRAL Y SUS COMPONENTES}

El tema que va a ocuparnos en este tercera parte de nuestro estudio de los motivos paganos en los mosaicos orientales es del mayor interés. Se trata, básicamente, del Zodíaco, el más conocido de los motivos que fueron escogidos por los antiguos judios para la decoración de los pavimentos de sus sinagogas en Palestina durante el periodo bizantino. Pero su relación con motivos que se encuentran también esporádicamente en iglesias u otros ambientes cristianos de la misma época es tan estrecha, que no podemos más que tratarlos juntos para obtener una mayor comprensión del significado de cada uno de ellos. En efecto, el sol, la luna, las estrellas, las doce constelaciones, los doce meses y las cuatro estaciones del año forman un conjunto artístico difícil de dividir, y sería absurdo querer estudiar cada uno de ellos por separado por el hecho de que no se encuentren siempre todos ellos en un mismo mosaico. Por otra parte, el hecho de que, tanto los judíos como los cristianos, estuviesen profundamente influenciados por la cultura y la religión del mundo pagano que les rodeaba, nos obliga a revisar primero la expresión de aquel mismo tema en el trasfondo cultural pagano, a fin de interpretar debidamente su consecuente uso por parte de judíos y cristianos y señalar las

Este artículo es continuación de los trabajos publicados bajo el mismo título en el número anterior.

1* Universidad Ben-Gurión, Beersheva, Israel. 
diferencias que separan los tres grupos en el modo de tratarlo y en su posible simbología.

\section{El fondo pagano}

Los investigadores están de acuerdo en aceptar el origen babilónico de la rueda del tiempo o Zodíaco, un esquema astronómico del tiempo basado en el aparente circuito anual del sol a través de doce constelaciones de estrellas. La duración de esta aparente conjunción del sol con cada una de las constelaciones equivale poco más o menos a la de un mes solar, y es por ello que, en las figuraciones clásicas del calendario o esquema atronómico del tiempo, las representaciones figuradas de los meses pueden aparecer junto a los correspondientes "signos zodiacales". Hay casos en que los meses, sencillamente, sustituyen a tales signos.

Fue sobre todo en Egipto donde el sistema zodiacal fue adoptado por el mundo helenístico, y donde fue desarrollado artísticamente en las paredes de los templos. En tiempos romanos, el Zodíaco era conocido y representado tanto en Occidente como en Oriente como elemento decorativo, sin que pueda hablarse ni de verdaderos calendarios prácticos ni de alegorías de carácter cúltico cuando sólo los encontramos ejecutados en mosaico en el pavimento de algunas casas señoriales. Pero ya aquí tenemos que introducir el hecho indudable de que dichos pavimentos, tanto por su temática como por su composición, tienen que ser considerados como el reflejo de una bóveda. Efectivamente, la forma circular y radiada inscrita en un cuadrilátero permite imaginar un punto central en lo alto, rodeado por formas trapezoidales de iguales dimensiones. Fuera del círculo, los cuatro ángulos corresponderían a los pendentivos que completan la bóveda. Es así como interpretan normalmente los historiadores del arte los mosaicos circulares centralizados, considerando como otros tantos elementos del techo las diversas cenefas y paneles que rodean el círculo por sus cuatro lados ${ }^{2}$. Esta observación tiene que servirnos luego para

2 Tratando del mosaico del calendario de Antioquía, escribe Lassus: “On est d'autant plus tenté d'y reconnaître une coupole que la bordure imite une rangée de caissons en relief. Bien sûr, c'est la voûte d'arêtes qui paraît avoir fourni l'origine des compositions les plus somptueuses... La mosaîque constantinienne des Saisons qui est au Louvre, accuse son caractère 
una mejor interpretación del Zodíaco en las sinagogas, por el hecho de que la representación del firmamento en la bóveda, en la que todo gira entorno a la figura central, que de algun modo representa la divinidad, es ciertamente una imagen del poder universal de Dios.

Pasando a la temática propiamente dicha de los mosaicos paganos con motivos referentes al tiempo (constelaciones, meses, estaciones, sol, año) tenemos que distinguir entre mosaicos de calendario, en los que aparecen las constelaciones o los meses sin referencia a un punto central, y los que sí tienen este punto de referencia, que son las figuras divinas de Helios o Sol, de Aion o Annus (personificaciones del sol y del tiempo o año), o de otras divinidades en Oriente. Entre los primeros se cuenta el descubierto en El Djem, Tunisia, en el que por primera vez están representados los meses. Estos aparecen dispuestos en cuatro filas sobrepuestas, de seis cuadrados cada una (Stern 1981: 436, PI. III). Un mosaico romano con las alegorías de los meses y de las constelaciones, de una gran belleza de composición y ejecución, es el muy conocido de Hellín, en Albacete, España ${ }^{3}$, hoy expuesto en el Museo Arqueológico de Madrid. Otro, también con meses y constelaciones, fue descubierto en Trier (LIMC, Menses, 28). Muchos más mosaicos y frescos con sólo los meses, a veces fragmentarios, pueden verse en el British Museum, procedentes de Cartago (Stern 1981: PI. XXXVII). Existía otro, hoy perdido, que ostentaba una composición circular de los meses, con las cuatro estaciones en los ángulos (ibid.: PI. XXXIX, 102).

Entre las representaciones centralizadas del mundo astral, habría que destacar primeramente la pintura que decora la bóveda del adytum

de voûte par des cadres qui sont des bandes dôves traitées en relief. Et la ressemblance avec les voûtes ravennates montre qu'il ne s'agit pas d'une illusion...». (LASsus 1975: 334). En Oriente, la tradición de la proyección de la cúpula sobre el pavimento parece continuar hasta los tiempos oméyadas: «... Mais, si nous évoquons ici les deux coupoles omeyyades [de $\mathrm{Kh}$. El Mafjar, cerca de Jericó], c'est parce qu'elles nous permettent mieux d'imaginer l'emplacement des 24 animaux de notre mosaique, par rapport à la partie centrale de celle-ci, en supposant, comme on le fait ailleurs, que cette mosaïque du sol reflète le décor d'un plafond et de la voûte qui la surmonte. Cette comparaison peut même ajouter un argument en faveur de la suposition que les mosaiques du pavement sont des projections sur la surface plane du sol des divers éléments du décor d'une voûte qui y sont fréquemment fixés sur des surfaces différentes (calotte, pendantifs, arcs)" (GRABAR 1983: 193).

${ }^{3}$ Se trata de un calendario con representación de escenas bucólicas, estaciones del año al centro, meses y constelaciones juntos, airededor. Todo en recuadros, particularmente octágonos (J. M. BLAzouez et al., Lérida y Albacete, en Corpus de mosaicos de España, Madrid, 1989. Fasc. VIII, Lám. 1819, 34-39). 
del templo de Bel en Palmira, en la que vemos al dios en el círculo central, sentado como un Pantocrator y rodeado por siete planetas. En un círculo celeste exterior, sin embargo, están inscritos los signos del Zodíaco. Y en los cuatro ángulos, como sosteniéndolo, aparecen cuatro sirenas dispuestas diagonalmente (Lehmann 1945: 3, fig. 3). Aquí tenemos ya el tema de la bóveda como el lugar más apropiado para representar a la divinidad gobernando el universo entero desde el centro de las esferas celestiales. No se trata pues de un calendario, como en los mosaicos mencionados antes, sino de la representación plástica de una realidad invisible pero creída por los fieles del dios Bel. No podemos dudar de que, en la mente de los que la realizaron, la representación figurada de la divinidad incluía ya su identificación con el sol, principio unificador de todos los elementos astrales y dador de vida para los habitantes de este mundo inferior. Esa identificación resultaba obvia en el mundo helenístico, en el que la divinidad central del universo era representada simplemente como el dios sol, Helios, radiante, ataviado con sus atributos y cabalgando en su carroza. Hay que tener muy presente, en la investigación del tema que nos ocupa, que «el sol» y «el dios sol» eran conceptos prácticamente inseparables en la mente de los antiguos. Y así es como hay que interpretar las apariciones del sol rodeado por los signos zodiacales en mosaicos y otros monumentos de origen pagano, tanto en el mundo helenístico y romano como fuera de él, aunque bajo su influencia cultural. Lo encontramos, por ejemplo, en el mitreo de Dura Europos (Perkins 1973: Pl. 35), en un disco en el que los signos zodiacales rodean el relieve del dios Mitra matando al toro ${ }^{4}$. Entre los Nabateos, la divinidad cuyo busto en relieve, rodeada por la franja zodiacal, fue hallado en el templo de Khirbet et-Tannur, hoy en territorio jordano, es Tyche, la protectora de las ciudades (Glueck 1952). En Roma, en cambio, vemos la misma franja rodeando a un Zeus entronizado (Blázquez 1981: 187).

En cuanto a elementos separados del cuadro astral o del calendario figurado, encontramos en el mundo pagano muchísimas representaciones de los meses del año, ya solos, ya en conjunción con las constelaciones (Levi 1941; Stern 1981). En los mosaicos, la disposición más corriente en que aparecen es dentro de recuadros en el pavimento de casas señoriales, como ya vimos. Por otra parte, las constelaciones o

4 Otro ejemplo conocido es el procedente de Londres, aducido por BLAzQuEz 1981: 187, ก. 160 
signos del Zodíaco aparecen algunas veces alrededor de una figura humana central, que no es la del sol sino la de Aion (el tiempo, la eternidad) o la de Annus (el año). Los dos casos se encuentran en mosaicos de Haïdra, Tunisia ${ }^{5}$. En cuanto a las figuras femeninas que acostumbran a cubrir los cuatro ángulos del cuadrado en el que está inscrito el círculo zodiacal, ya vimos que en el templo de Bel eran cuatro sirenas, seres benéficos al servicio de los dioses y de los hombres. Lo mismo encontramos ya en Etruria, en la llamada Tumba del Mono (Lehmann 1945: 2-3). En la mayoría de los mosaicos romanos y bizantinos con temas centralizados, las figuras representadas en aquel lugar preciso son las de las cuatro estaciones del año, también ellas representadas como cuatro mujeres, ataviadas con sus atributos respectivos. Hay que recordar que, en griego por lo menos, los nombres de las cuatro estaciones son de género femenino. Estas estaciones, que dividen el año en cuatro períodos de igual longitud, podían tener mucha importancia en los calendarios zodiacales, a pesar de que no siempre se las hace corresponder con los meses o constelaciones pertinentes, como veremos. Numerosos son los mosaicos orientales de los períodos romano y bizantino en los que se nos han conservado, en parte por lo menos, las figuras de las estaciones. Así, en en un ángulo del mosaico de $\mathrm{Ca}$ siopea en Palmira (Balty 1981: PI. XXXIX) y en una villa de Apamea, donde vemos a dos estaciones acompañando a la Tierra, Ge (Balty 1973). En la villa romana de Awza'i, en el Líbano, tenemos la repre-

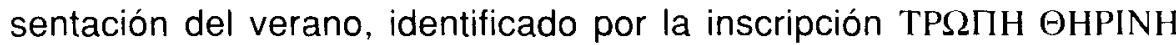
(Chéhab 1958: PI. LXXXVI, 2). De la época de los Severos, copia de una pintura original del primer siglo del siglo । (según Balty), encontramos los bustos de las cuatro estaciones en medallones, en un mosaico que tiene como tema principal las musas y los filósofos, hoy en el Museo de Pérgamo en Berlín (Balty 1981: 415-416, PI. XXXVIII, 2). Igualmente las encontramos en mosaicos de villas y casas señoriales de la antigua Palestina, como en la villa romana de Bet Guvrin (Vincent 1922; Avi-Yonah 1981: PI. 49), en un mosaico de Cesarea (WeissTalgam 1980), y ahora en la villa rústica de 'Ein Ya'el, cerca de Jerusalén (Roussin 1995: 32, Figs. 3 y 4). Más allá del Jordán las vemos también, en ambiente no religioso, en la llamada Sala de las Estaciones de Mádaba (Piccirillo 1993: 71, Figs. 35, 41-42), y en los ángulos de la Sala de Hipólito, también de Mádaba (ibid. 51, 60, Figs. 3, 13, 14).

5 Para Aion véase $L I M C$, AION 13,16,18,20, 22. Para Annus, LIMC, ANnus 5, 8. 


\section{El Zodíaco en el pavimento de las sinagogas de Palestina}

Es sólo a partir del s. IV d.C. que aparece una decoración musiva en el pavimento de las sinagogas palestinas. Mosaicos se encuentran ya en la sinagoga de Sardis, en Asia Menor, pero son de carácter anicónico. Representaciones figurativas en grandes frescos murales las tenemos en la sinagoga de Dura Europos, en Siria, a mediados del siglo III d.C. Pero el tema de la rueda del tiempo o Zodíaco, tema que había sido representado ya infinidad de veces en ambientes paganos ${ }^{6}$, lo encontramos por primera vez en el judaísmo en la sinagoga de Hammath Tiberias, en Galilea, en su primera fase de construcción, que se fecha en el s. IV (Figs. 1, 2, 22). Luego aparece en muchas otras sinagogas de la Palestina bizantina, durante los siglos $v$ y vI. Es notable el hecho de que tal tema no se encuentra representado como tal ni una sola vez en las numerosísimas iglesias del mismo período, ni en Palestina ni fuera de ella, aunque sí existe en iglesias posteriores, de estilo románico, particularmente en el norte de Italia. Pero hay que advertir que el tema de la rueda del tiempo, con personificaciones de los doce meses del año en vez de los signos del Zodíaco, y con las dos figuras del sol y de la luna en en el centro, decora el pavimento de una sala central (tal vez un patio interior) en el monasterio bizantino del siglo vi llamado de Doña María, en Bet Sheán-Escitópolis, en Galilea (Fig. 19), como luego comentaremos (pp. 172-177). También dentro del área de la antigua ciudad de Bet Sheán-Escitópolis, en El-Hammam, se conserva un gran fragmento de otro mosaico procedente de una una tumba cristiana con las representaciones de los trabajos de los meses, aunque dispuestos de un modo muy distinto que los del mencionado monasterio. Los personajes, identificados tanto por sus atributos como por sus respectivos nombres en griego, aparecen entre plantas en dos filas sobrepuestas (Fig. 20) (Foerster 1993: 231). La abundancia de plantas y frutos dan un carácter agrícola y de representación de la tierra a esta aparición de los meses del año, lo que nos acerca más al bien al significado general del pavimento de todas las salas de culto, tanto judías como cristianas, y nos impide entretenernos en cualquier elucubración sobre un significado simbólico de los detalles.

6 De hecho, una composición musiva idéntica a la de las sinagogas palestinas, es decir, de la rueda del Zodíaco alrededor de la figura de Helios, solo se nos ha conservado en dos mosaicos de villas romanas en de Europa central: en Avenches, Suiza, de mediados del s. II! d.C. y en Bingen, Alemania, cerca de Maguncia (Roussin 1997: 83). 
En las sinagogas, el Zodíaco, o banda circular entre dos círculos concéntricos en que aparecen en forma radiada las representaciones de las doce constelaciones personificadas, separadas una de otra en compartimientos iguales, rodea generalmente la figura central del sol, representado bajo la clásica figura de Helios. Los cuatro ángulos del cuadrado en que está enclavado el círculo del Zodíaco están siempre decorados con los bustos de las cuatro estaciones del año personificadas, cada una con sus atributos. Hay poca varidedad en los detalles, pero el estilo puede ser muy diverso de un ejemplo a otro (Figs. 1, 4, 7, $9,10,11,14,22)$.

El tema que nos ocupa ha sido tratado infinidad de veces por parte de los historiadores del antiguo arte judío, tanto por la forma y el estilo de las representaciones de las constelaciones y del sol, como por la aparente paradoja de la aparición de tal tema, de origen evidentemente pagano, en un recinto consagrado al culto judío. Cada uno de los elementos que integran el tema era tratado con el ropaje mitológico usual en el mundo clásico. El sol era representado bajo la figura divina de $\mathrm{He}$ lios. Las doce constelaciones aparecian en forma de figuras humanas, algunas incluso desnudas ${ }^{7}$. Las constelaciones eran un elemento de culto pagano explícitamente prohibido por la ley judía a causa de la influencia que se les atribuía sobre los acontecimientos de esta vida. Es realmente sorprendente, a primera vista por lo menos, encontrar ese conjunto pagano en las sinagogas del país de Israel ${ }^{8}$, en una época en que la vida religiosa judía era regida por aquellos mismos rabinos que habian tomado parte en la composición del Talmud, el código oficial del

Véase como describe M. Avi-Yonah el carácter pagano de los elementos que integran el Zodiaco en las sinagogas de Hammath Tiberias y de Bet Alfa: «Déjà dans les représentations du Zodiaque on note beaucoup de caractères païens, surtout à Tibériade. L'image de la Vierge est celle de Koré-Perséphone, le Verseau est un athlète nu, la Balance, un homme qui tient un sceptre, c'est Minos ou Rhadamaanthe; Hélios a tous les attributs d'un dieu solaire: l'auréole, le globe céleste etc. A Beth Alpha, les images sont prises dans le répertoire byzantin: la Vierge est assise sur son trône, porte les souliers rouges et le diadème d'une impératrice; le Sagittaire, la Balance et le Verseau sont tous représentés en tunique brodée comme les serviteurs à Piazza Armerina ou sur les pavements du Grand Palais à Constantinople». (AVI-YONAH 1981).

8 Además de encontrarlos en mosaico, los signos del Zodiaco aparecieron también, junto con una cabeza de león, en un fragmento de cancel decorado con altorelieves que parece de sinagoga, en el pueblo de Kafar Birim (Bir'am), en el norte del país de Israel (GooDENOUGH 1953-1958, vol. 3, figs. 513-515). Los signos zodiacales decoraban también algunas de las baldosas recobradas del techo de la sinagoga de Dura Europos (KRAELING 1956: 42, pl. 9: 1-3). 
comportamiento moral y religioso considerado como normativo para todos los judios.

Las sinagogas palestinas conocidas hasta el presente que ostentaban la rueda del tiempo como motivo central del mosaico pavimental son las siguientes:

1. Hammath Tiberias (Figs. 1, 2, 22), situada a un par de kilómetros al sud de la actual ciudad de Tiberíades, junto al Lago de Galilea. El nivel en que se encuentra el mosaico se fecha el s. IV ${ }^{9}$.
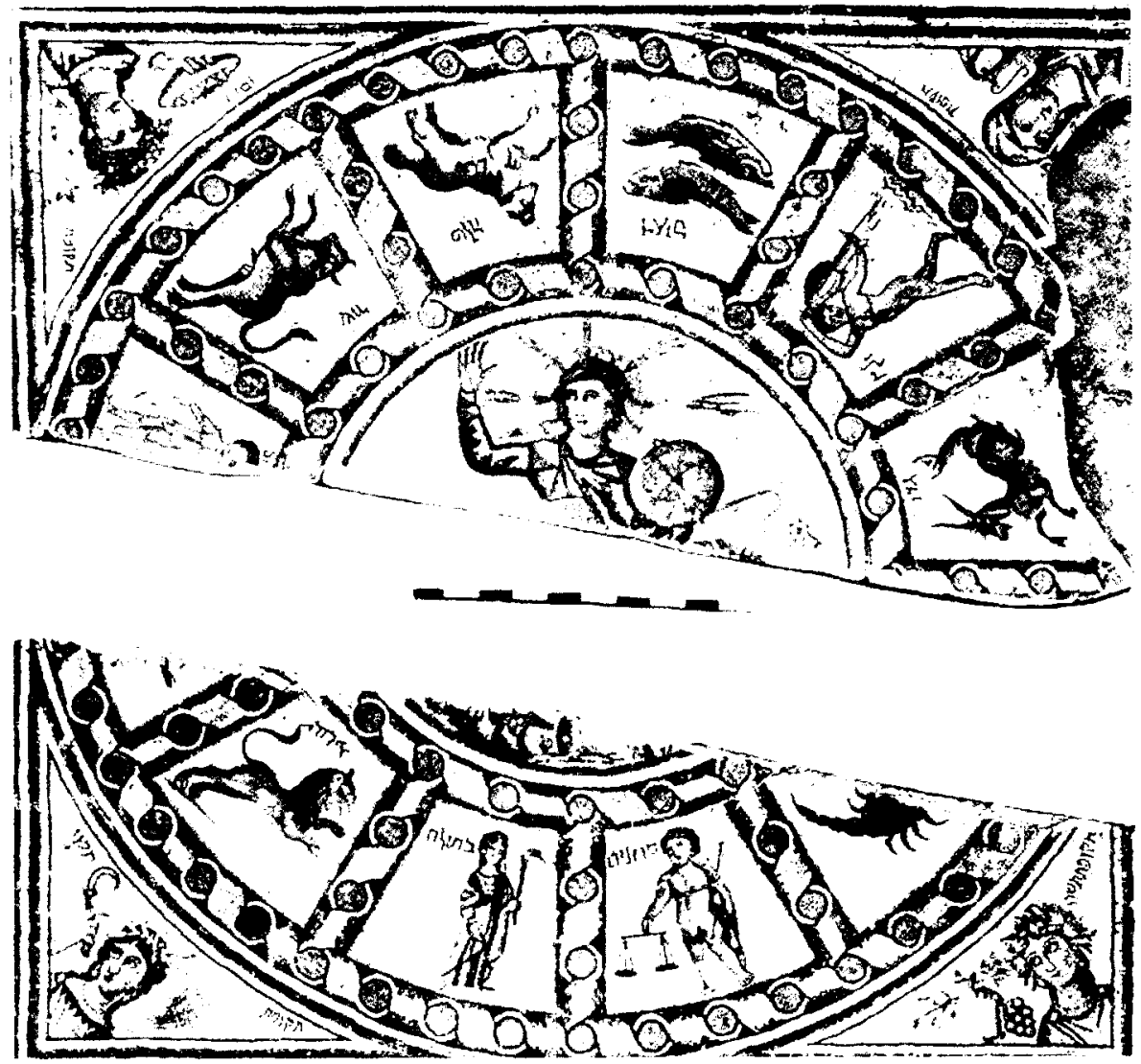

Figura 1. Zodiaco. Sinagoga de Hammath Tiberias (DoTHAN 1993: 576).

9 DOTHAN 1968; id. 1983 and 1993; WILKINSON 1978: 25, fig. 9. 


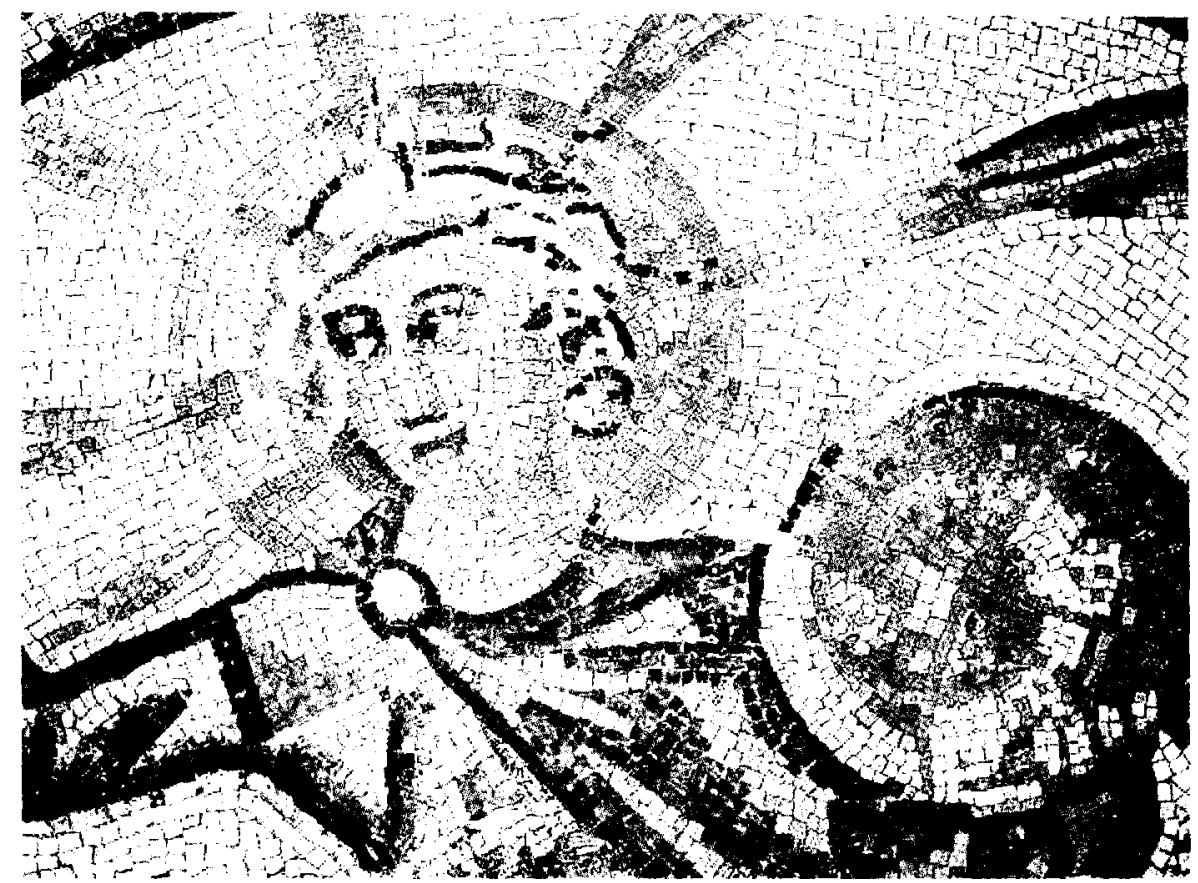

Figura 2. Helios. Sinagoga de Hammath Tiberias (Foto I. GRINBERG).

2. Naarán (Figs. 3 y 4), a un $\mathrm{km}$. al norte de Jericó. Su mosaico fue en gran parte destruido por los iconoclastas, y sólo en parte restaurado en la antigüedad. Se fecha en el siglo vi ${ }^{10}$.

3. Horvat Susiya (Fig. 5), la única de las sinagogas con Zodiaco que se encuentra en el territorio de Judea propiamente dicha, al sur de la ciudad de Hebrón. Pero sólo queda un fragmento del circulo original ${ }^{11}$.

4. Bet Alfa (Figs. 6-8), en el kibbutz Heftzibah, en la llanura de Bet Sheán, junto al monte Gelboé, la mejor conservada. Está fechada en la época del emperador Justino, probablemente Justino II, a finales del s. $\mathrm{vI}^{12}$.

10 VINCENT-BENOIT 1961: 161-177 y pl. V-XXIII; WILKINSON 1978: 18, fig. 3; STERN, 1993 : $1075-1076$

1 GUTMAN el al 1972, RB $421-422$ y pl. XL; Id., 1978: 1125; Qad 5 (1972) 47-52 (en hebreo). SUKENIK 1932; CHIAT 1980: 14, fig. 9; WILKINSON 1978. 


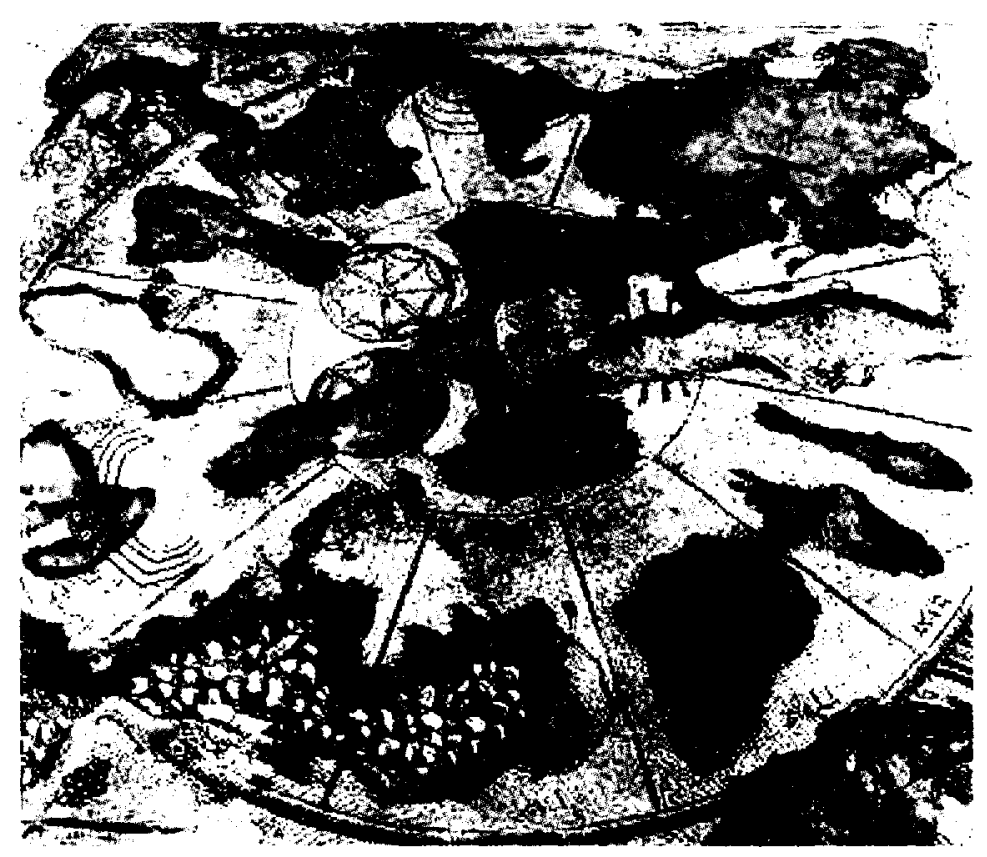

Figura 3. Sinagoga de Naarán. Rueda del Zodíaco (HaCHLILI 1988: pl. 74).

5. Huseifa (Figs. 9 y 10), situada en la actual aldea drusa de 'Isfiye, en el Monte Carmelo. El centro de su Zodíaco está casi totalmente destruido, pero se conservan parcialmente cinco de los signos, de Sagitario a Capricornio. El mosaico se fecha a principios del s. vI ${ }^{13}$.

6. Séforis (Figs. 11-14). Esta sinagoga fue descubierta hace pocos años (Weiss-Netzer 1997), y nos proporciona unos elementos de comparación temática totalmente nuevos, que nos son de gran utilidad para una mejor interpretación del Zodíaco en las todas las demás, puesto que cada uno de los doce compartimientos de la rueda del tiempo incluye tanto los signos del Zodíaco como los meses del año hebreo personificados y definidos con sus respectivos nombres ${ }^{14}$. Es significativo, además, que la figura central del sol está aquí identificado por

\footnotetext{
AVI-YONAH 1933.

4 TALGAM 1998: 87 (otoño - tishrei, en foto).
} 


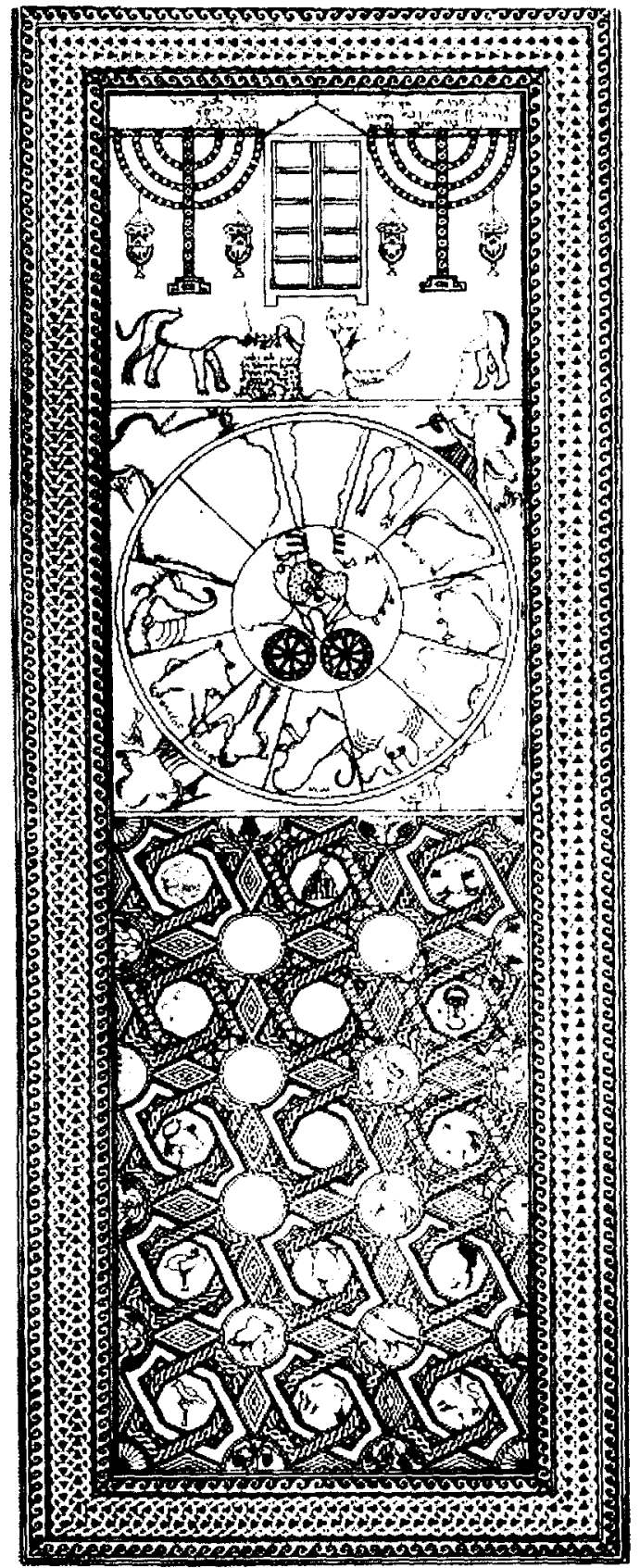

Figura 4. Sinagoga de Naarán. Pavimento de mosaico (HACHLll 1988: 358, fig. 11). 


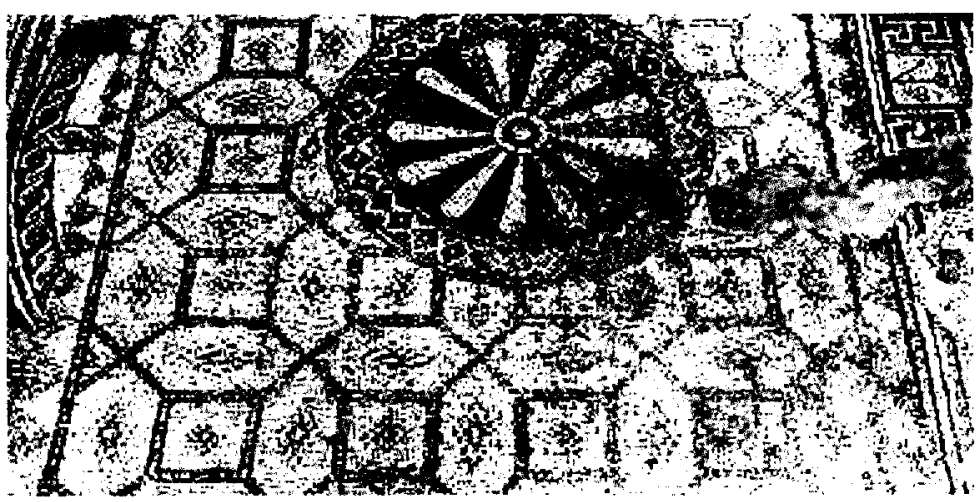

Figura 5. Sinagoga de Susiya. Restos de la rueda del Zodíaco en el mosaico (HACHLILI 1988: pl. 75).

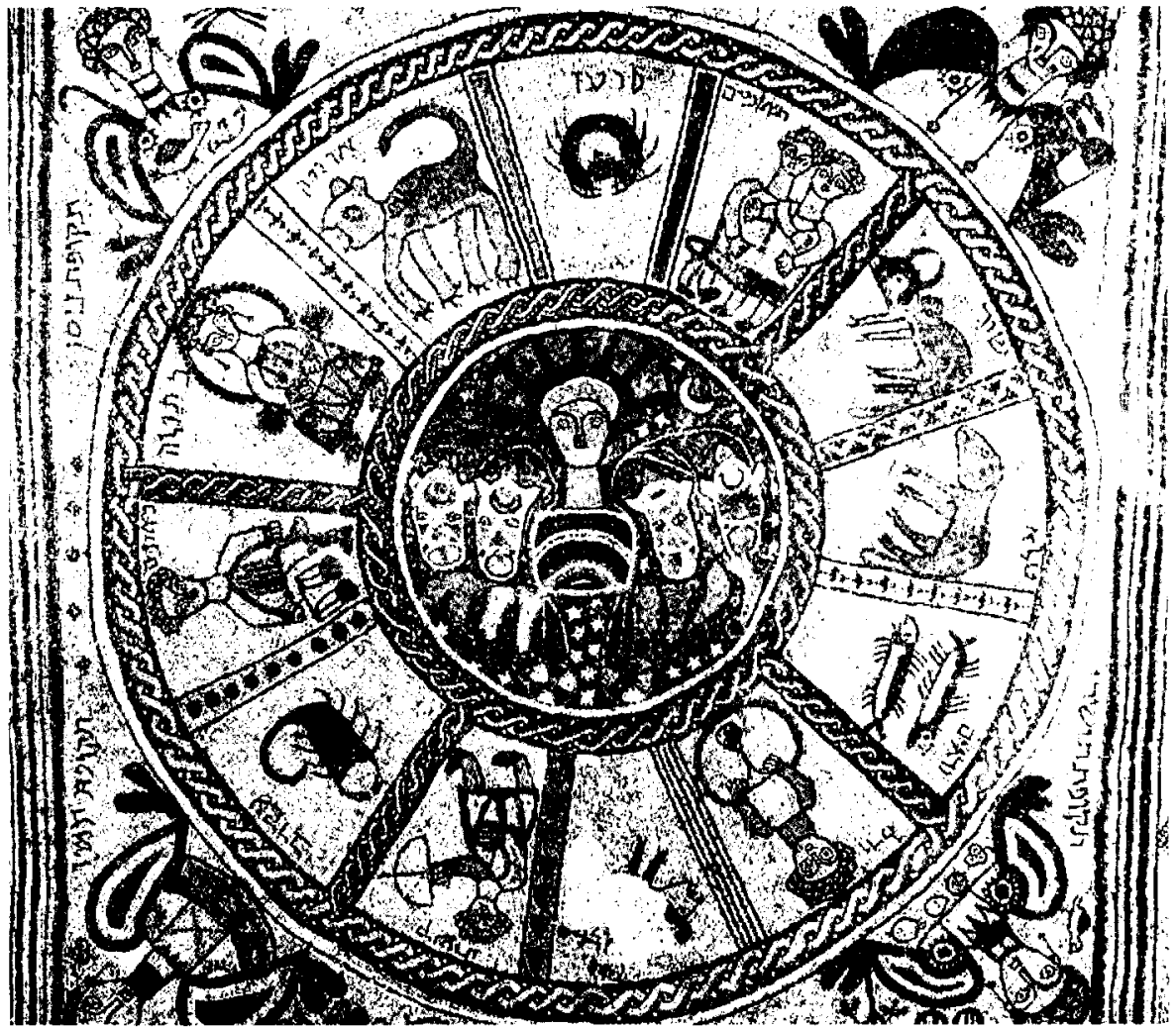

Figura 7. Zodíaco. Sinagoga de Bet Alfa (OVADIAH 1993: 43). 


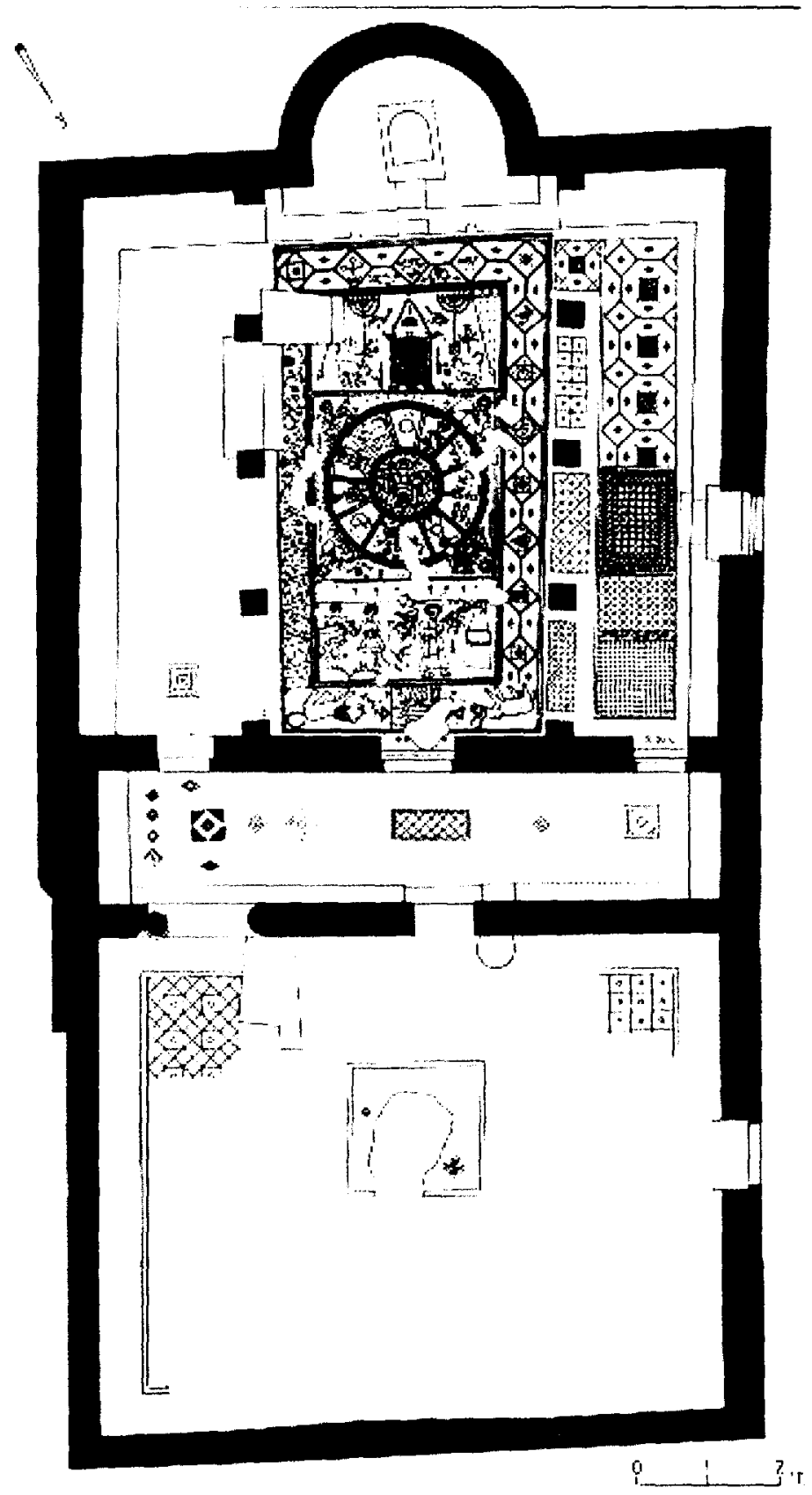

Figura 6. Plano de la sinagoga de Bet Alfa (HACHLILI 1988: 350, fig. 3). 


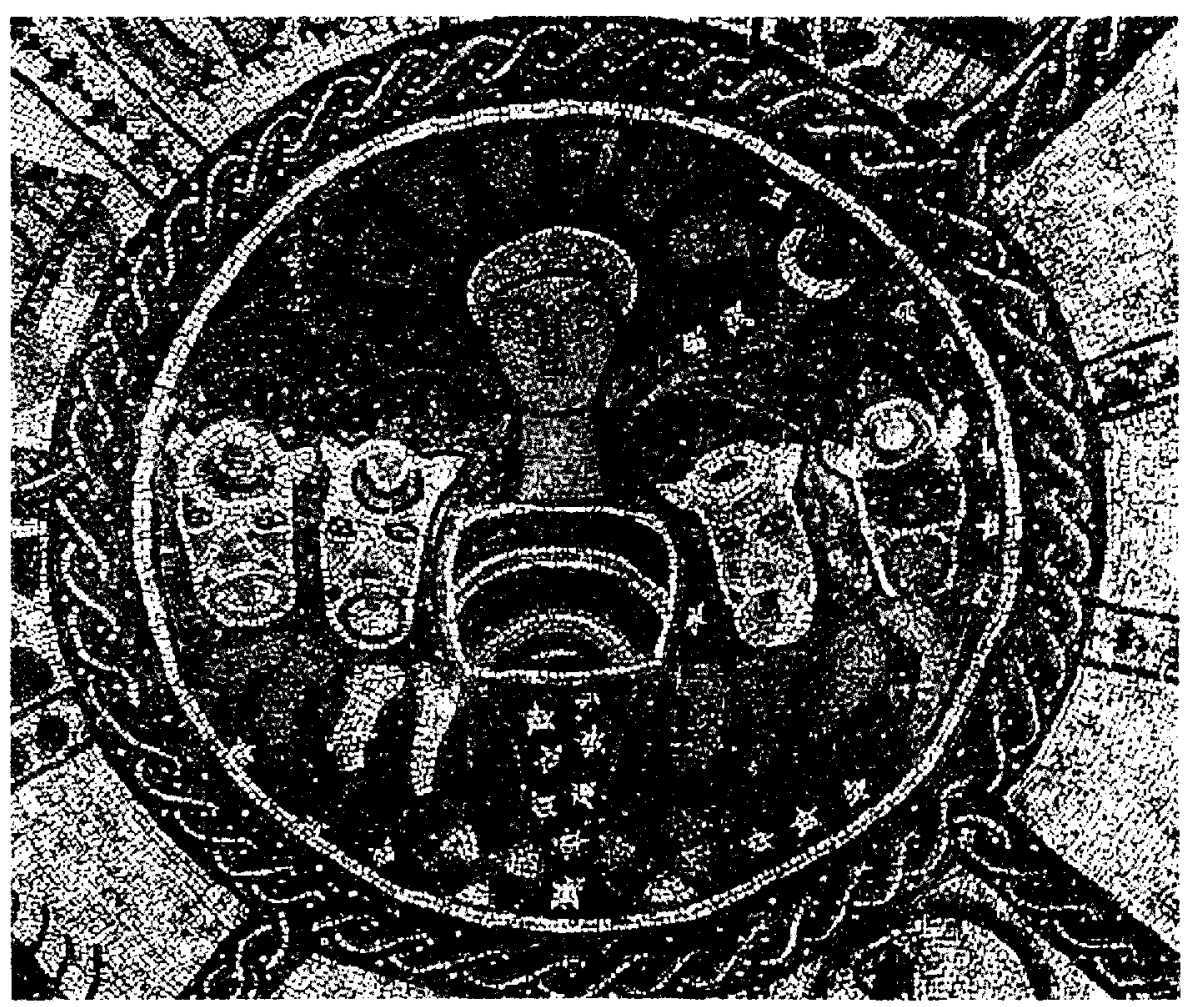

Figura 8. Helios. Sinagoga de Bet Alfa (Foto I. GrinBERG).

un disco del que salen rayos y no por la representación del dios Helios (Fig. 12).

No podemos más que lamentar el mal estado de conservación de la mayor parte de aquellas composiciones musivas, aunque, afortunadamente, algunas han sufrido un deterioro muy leve. Así la de Bet Alfa, que por otro lado es la más apartada de los precedentes clásicos y tal vez la más tardía (s. vi), exhibiendo un estilo puramente local, frontal, ingenuo, por no decir infantil, lo cual no quiere decir que esté desprovisto de gracia y originalidad (Figs. 7 y 8 ). La más tradicionalmente clásica, la de Hammath Tiberias, que es también la más antigua (s. IV), sufrió en el siglo $v$ la sobreposición de un muro, de un espesor de medio metro, que, atravesándola diagonalmente, dañó parte de algunas constelaciones y del medallón central. Pero el buen estado general y las pocas reparaciones de que fue objeto con ocasión de su ex- 


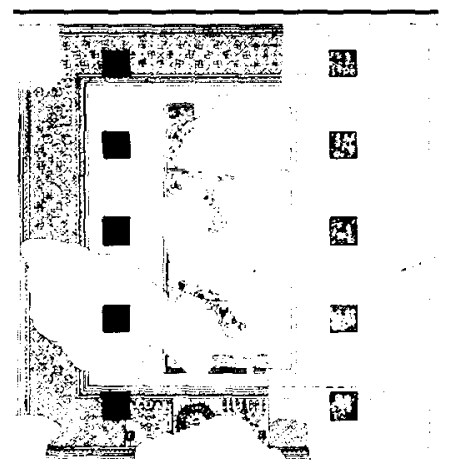

Figura 9. Plano de la sinagoga de Huseifa (HACHLIL 1988: 352, fig. 5).

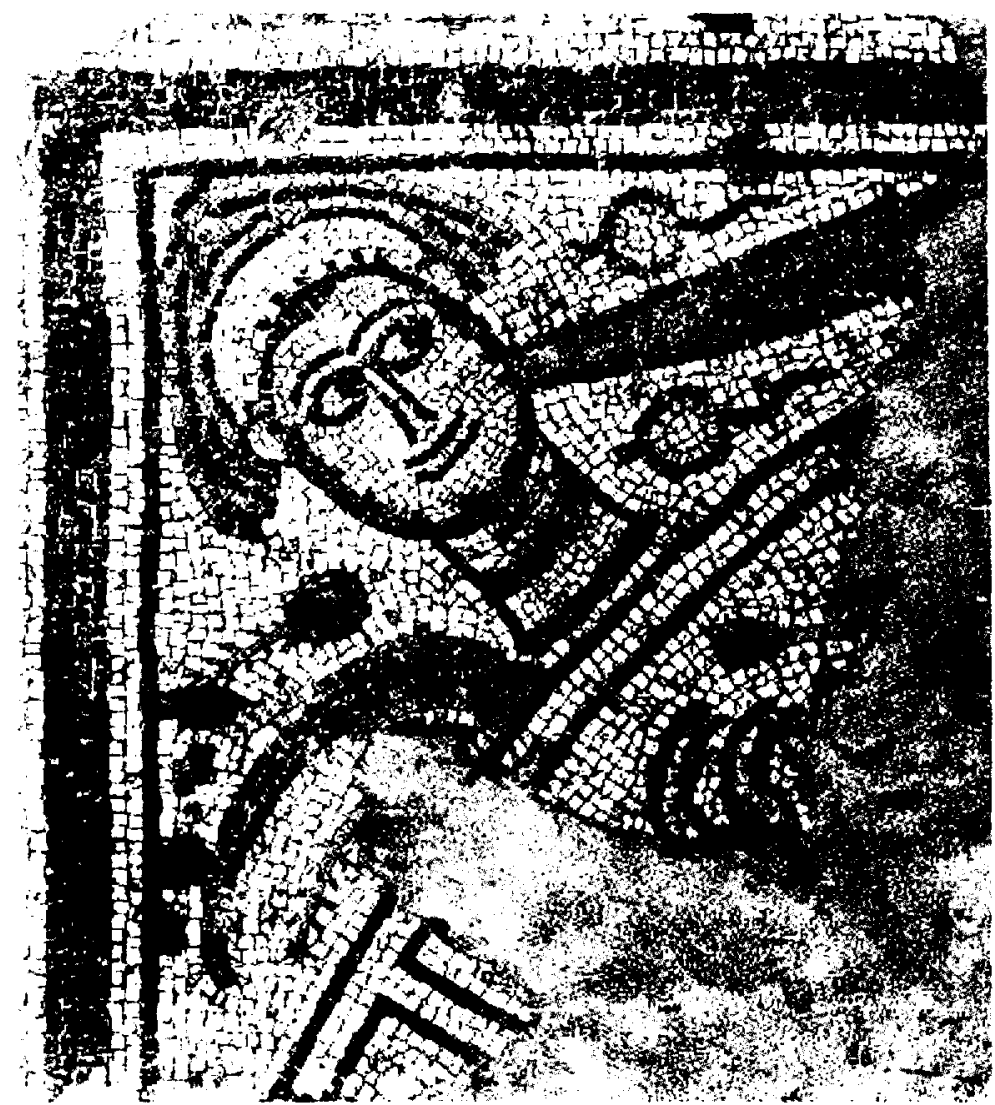

Figura 10. Estación. Sinagoga de Huseifa (AVI-YONAH 1933: pl. XLIV, fig. 1). 


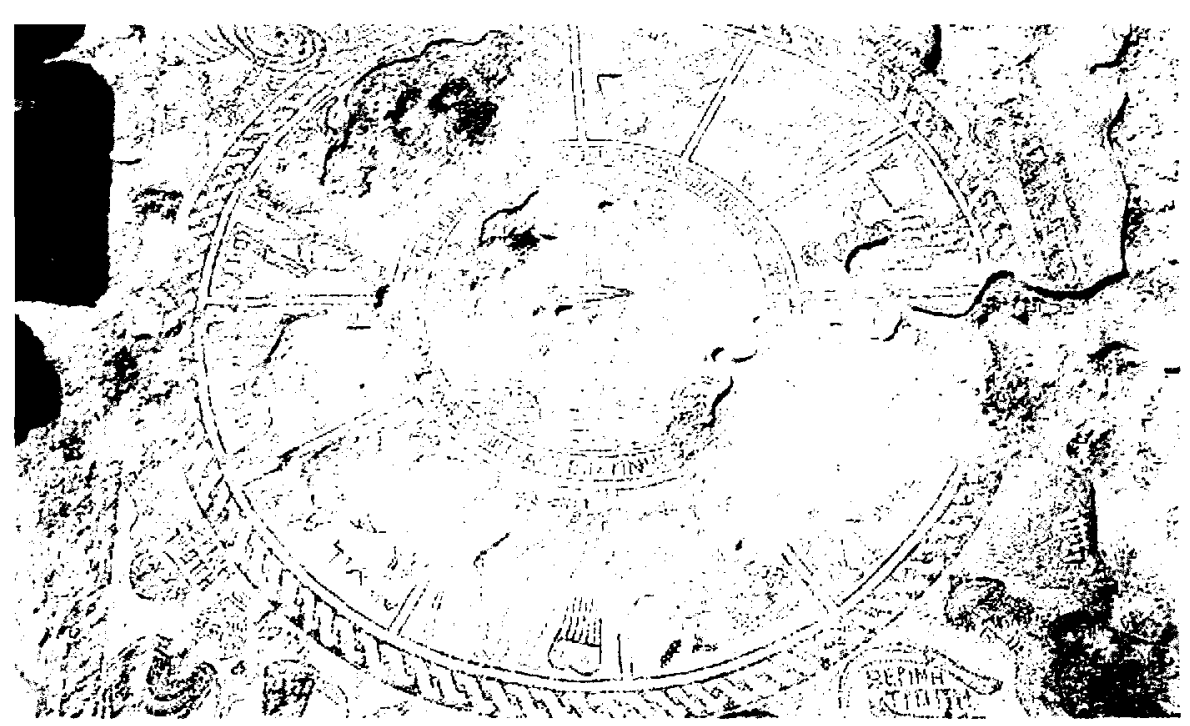

Figura 11. Sinagoga de Séforis. Zodiaco con constelaciones y meses (WEISS-NETZER 1997; pl. 3).

cavación permiten el aprecio objetivo de sus cualidades estilísticas y temáticas sin dificultad alguna (Figs. 1, 2, 22).

Las demás representaciones del Zodíaco en sinagogas son todas bastante parciales, como se puede apreciar por las ilustraciones. Se distingue perfectamente el tema general, además de que quedó intacta una gran parte de las inscripciones. En las sinagoga de Huseifa (Fig. 9), el deterioro de los mosaicos se debe a la destrucción o abandono general del edificio. Pero se reconocen bien algunas constelaciones y una de las estaciones (Fig. 10). El Sagitario está representado como "una figura desnuda con un manto amarillo tirado sobre un hombro, semejante a la piel de león de Hércules» (Avi-Yonah 1993: 638). En la de Naarán (Figs. 3 y 4), los mosaicos pasaron por las manos de los iconoclastas, probablemente a finales del s. VII o principios del VIII, quienes intentaron borrar todas las imágenes humanas y de animales. La figura central, Helios, tenía la cabeza radiada y cabalgaba sobre una carroza tirada por caballos, de la que quedan sólo las ruedas. Pero el caso más interesante es sin duda el que se produjo en cierto momento en el pavimento de la sinagoga de Horvat Susiya, cuando el círculo del Zodíaco que verosímilmente adornaba el pavimento fue cambiado por otro moti- 


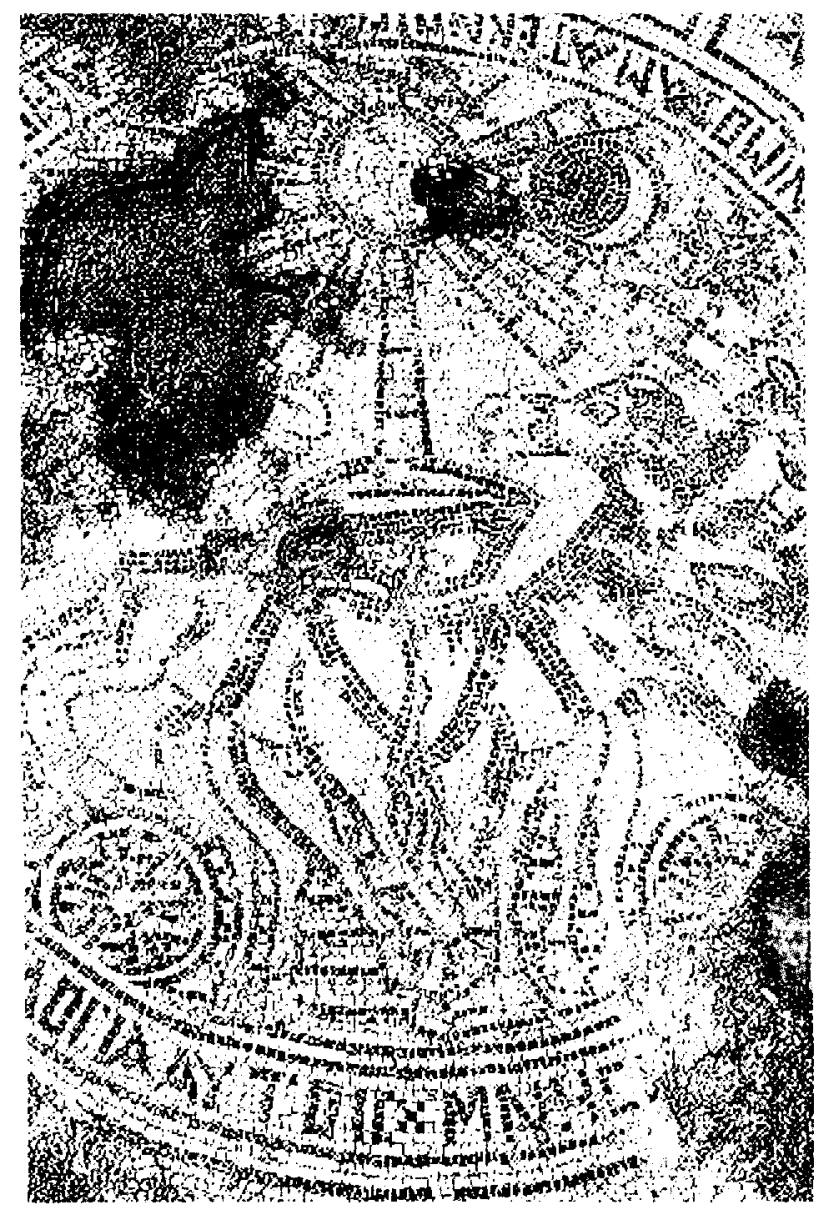

Figura 12. El carro del sol. Sinagoga de Séforis (WEISS-NETZER 1997: 19).

vo decorativo de tipo puramente geométrico (Fig. 5). Por este hecho resulta evidente que lo que tiene de paradójico para nosotros la visión del Zodíaco en lugar de culto judío lo tuvo también, en cierto momento, para los responsables del mismo, quienes acabaron por suprimirlo. Este fenómeno es la prueba de que una interpretación demasiado obvia de la presencia del Zodíaco en las sinagogas, como pudiera ser la de su función únicamente como calendario, no puede ser aceptada sin más. Es nuestro deber intentar penetrar en el significado del tema, teniendo muy en cuenta que faltan evidencias, tanto de orden arqueológico como literario, para poder dar una interpretación totalmente objetiva. 


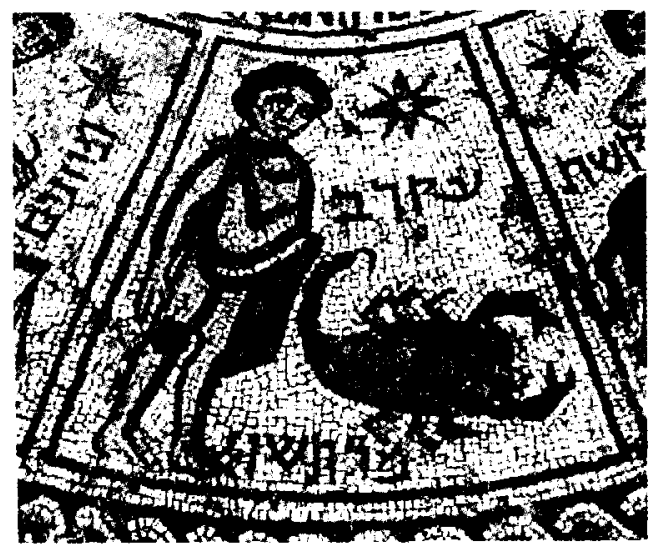

Figura 13. Akrav (Scorpio) y Marheshván. Sinagoga de Séforis (WEISS-NETZER 1997: pl. 4).

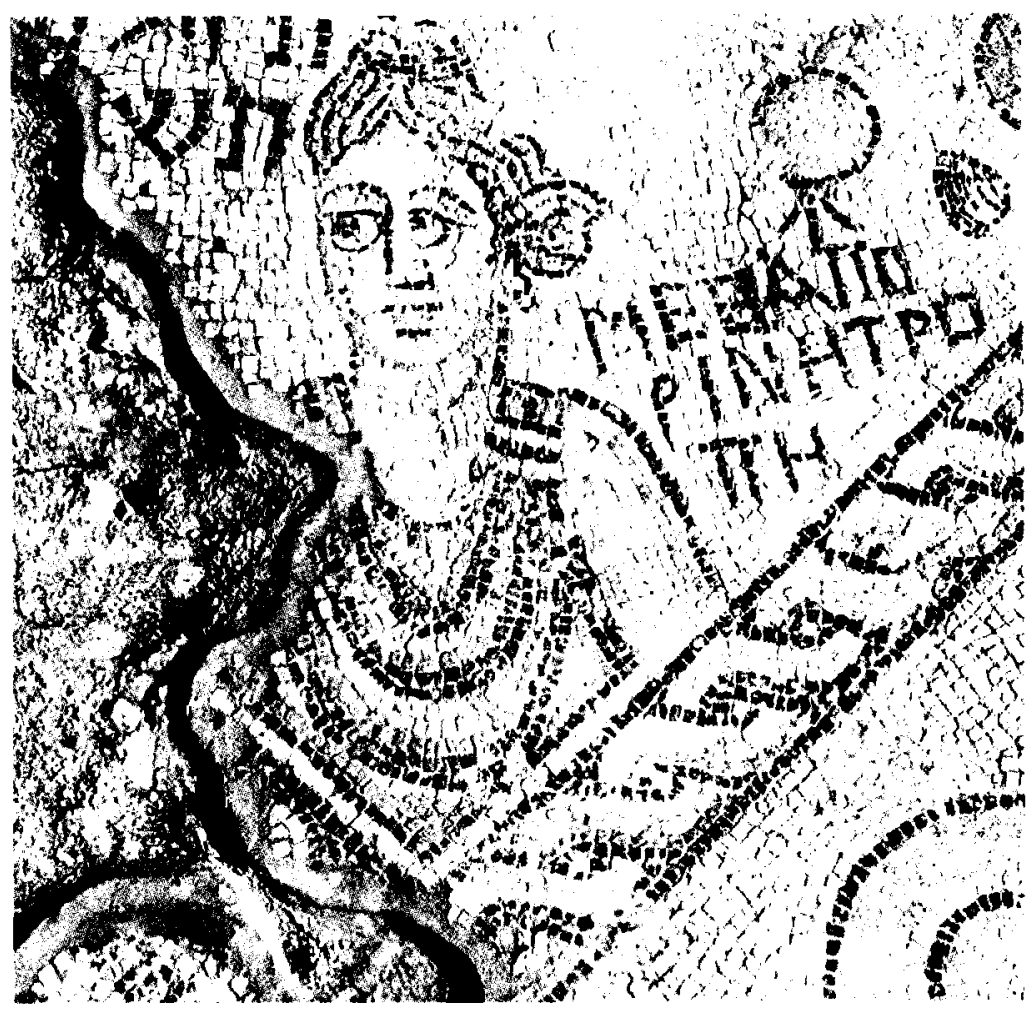

Figura 14. Otoño. Sinagoga de Séforis (TALMAG 1998: 87). 


\section{Significado del Zodíaco en el pavimento de las sinagogas}

Las muchas y variadas interpretaciones que se han dado a la cuestión pueden resumirse en del siguiente modo:

1. Teniendo en cuenta que el objeto primario del mosaico en las sinagogas es el hecho de constituir el pavimento, el Zodiaco debe considerarse antes que nada como un elemento decorativo, como hubiera podido serlo en las casas de los ricos del tiempo.

2. La disposición de los paneles decorativos en los pavimentos sinagogales, que tienen en el centro la rueda del Zodíaco y más al interior la representación del arca santa de la Torá (Figs. 4 y 6), es intencionada. En efecto, la parte pavimentada con la rueda del Zodíaco representaría la sala del hejal en el antiguo Templo de Jerusalén, y la parte pavimentada con el arca santa representaria el devir o "Santo de los Santos". Así interpretado, el ambiente entero de la sinagoga sería una reproducción del Templo, según J. Wilkinson (1978: Bet Alfa). Esta teoría queda corroborada, naturalmente, por el hecho de que ya el mismo Templo de Jerusalén parece tener, por su forma, una connotación cósmica (Daniélou 1953). En efecto, tanto la forma circular como la cuadrada o cúbica eran usadas para representar el cosmos (Tomasevic 1995: 285-287). Hay que tener en cuenta que ya en el siglo I Josefo Flavio afirma que, mientras que "las siete lámparas (del candelabro de los siete brazos) representaban los planetas, los doce panes depositados sobre la mesa simbolizaban el ciclo del Zodíaco y del año" (Guerra Judaica $V, 5,5)$. Es significativo lo que el mismo escritor judío había indicado en el párrafo anterior al citado, que «el velo (la parójet del Templo) contenía también historiada toda la visión del cielo, a excepción de los signos del Zodíaco" (ibid. V, 5, 4). Esto significa que, sólo la prohibición del uso de figuras humanas y animales había impedido que en la decoración del Templo mismo aparecieran ya los signos zodiacales. La idea, sin embargo, de imaginar el cosmos entero delante la presencia de Dios estaba bien implícita en la interpretación simbólica que se daba de aquellos elementos de culto mencionados, la «menorá» y los «panes de proposición".

3. Semejante a la anterior es la interpretación defendida por L. A. Roussin, que ella basa sobre el tratado místico judío llamado Sefer HaRazim (El Libro de los Secretos): la triple disposición de la decoración pavimental de las sinagogas es intencionada: la parte inferior (es decir, la más apartada del Arca Santa) representa el mundo terrenal; la 
central, esto es, «el panel de Helios dentro del zodíaco, representa la esfera celestial; la parte superior, "el panel con el Arca de la Torá, es símbolo del séptimo firmamento, donde, según el Sefer HaRazim, reside Yahvé, reinando sobre todos los reyes de la tierra, exaltado por encima de ellos y exaltado entre los ángeles del cielo». Apoyándose en este mismo texto y en el hallazgo de amuletos mágicos judíos con representaciones de Helios, "es posible sugerir, dice Roussin, que el Helios en los pavimentos de sinagoga represente una dividad menor, a la que algunos miembros de la comunidad podrían haber dirigido sus plegarias. No a la figura en sí misma, sino a la divinidad que representa" (Roussin 1997: 93).

4. El Zodíaco debe ser considerado como un calendario, ejecutado con el intento de conjuminar el calendario solar con el lunar y destinado a ayudar a la fijación de las fiestas judías. Es la interpretación más aceptada por los investigadores (Hachlili 1977; Dothan 1983, etc.), aunque con diversidad de matices. Ella se basa principalmente en el hecho de que el pavimento musivo de la sinagoga de 'Ein Guedi, que no ostenta la rueda del Zodíaco sino un emblema geométrico con cuantro elegantes aves dentro, contiene también una larga inscripción en arameo en la que se enumeran las doce constelaciones y los doce meses del año judío, además de los tres patriarcas y los tres amigos de Daniel (Levine 1981). Las consecuencias de este descubrimiento fueron puestas en evidencia por M. AviYonah, quien vio la relación que había entre la disposición de las doce constelaciones, los doce meses del año, y el período de servicio sagrado que debía ejercer cada una de las veinticuatro familias sacerdotales en el Templo de Jerusalén (Avi-Yonah 1981: 396-397) ${ }^{15}$. Para Guidoni (1983: 253), el énfasis no debe de ponere tanto en la función litúrgica de tal calendario, sino más bien en el significado general de las representaciones cosmológicas: "La identificación de los signos zodiacales con los meses del año e incluso las estaciones aluden a la tierra y a sus frutos, a los trabajos del campo: una representación de la vida terrestre, sobre la que se refleja el pasar del tiempo". Por su parte, Hanfmann (1980: 80-81) comenta que el Zo-

15 Avi-Yonah se inspiró en el hallazgo hecho en Cesarea Marítima de una doble lápida inscrita con los nombres de las veinticuatro familias sacerdotales, las semanas de su servicio en el Templo y los nombres de los pueblos en que se habían refugiado después de la destrucción de aquél (AVI-YONAH 1968). 
díaco no está en las sinagogas para comunicar un conocimiento enciclopédico neutro, sino que su función es la de ilustrar la creación por parte de Dios del sol y la luna, los signos y los días y los años, tal como se describe en el primer capítulo del Génesis.

5. Teniendo en cuenta el lugar que ocupa el Zodíaco en la mayoría de sinagogas que lo ostentan, siempre a segundo plano con respecto a la representación del arca santa de la Torá, probable símbolo del Templo celestial, el Zodíaco podría simbolizar la trayectoria del alma del creyente judío, del plano terrestre al celestial, pasando por el mundo astral, el firmamento del sol y de las estrellas (Goodenough 1953-1956, vol. 3: 250-257). La idea básica de Goodenough, principal propulsor de esta interpretación mistica, es el valor atribuido al sol y a todo el firmamento como máximos símbolos del poder central de Dios en el cosmos. $Y$ como Goodenough toma la sinagoga de Bet Alfa como base de su interpretación, ve representadas en su triple panel (Fig. 6) las tres etapas de la trayectoria del alma, que debe elevarse desde el mundo terrestre con sus dificultades (sacrificio de Abraham) a las esferas astrales que representan el orden divino, la ley inmutable que rige el universo (rueda del tiempo dando vueltas alrededor del sol), para llegar finalmente al mismo santuario celestial de Dios (el arca de la Torá). De este modo queda salvada y revalorada la fe judía en un Dios único, creador de cielos y tierra, al propio tiempo que se exalta su fuerza creadora y sostenedora del universo entero.

6. Siguiendo la línea interpretativa del itinerario espiritual del alma, Goodenough pasa a un plano de interpretación más complejo al atribuir al Zodiaco de Bet Alfa un valor de cuadro escatológico: “Colocar símbolos celestiales y escatológicos en el suelo significa sacarlos del futuro y ponerlos como una 'escatología realizada', o mejor dicho, como una participación mistica, en la vida presente» ${ }^{16}$. Parece, pues, que el Zodíaco en las sinagogas estaría destinado a servir de medio visual para ayudar a los fieles judíos a recordar su destino espiritual y a vivirlo ya aquí y ahora.

16 El texto continúa con unas palabras de autodefensa que bien tenemos que admitir: "There is no way to prove this (or anything else connected with this study), and I do not assert it as a fact that these ceiling designs on the floor had such a meaning. I would only point out that categorical denial is just as unproved as categorical assertion" (GOODENOUGH VIII: 219). 
7. Una útlima interpretación del Zodíaco nos llevaría a ver en la particular disposición de los signos la representación de un mensaje mesiánico, con explícita alusión a la restauración del reino davídico (Stone 1953).

Ante tal variedad de interpretación resulta evidente una doble tendencia de base, esto es, o realismo o simbolismo. Pero hay que tener en cuenta que el arte antiguo, en su gran totalidad, no sufre tal disección. Basándonos en la literatura, que revela más fácil y abiertamente la intención de los escritores, uno no puede equivocarse al aceptar de entrada la múltiple existencia de varias intenciones en una misma obra de arte. La belleza de una estatua clásica puede ir destinada tanto a delectar los ojos de quienes la contemplan como a elevarles su mente hacia la belleza sobrenatural del mensaje del que puede ser portadora la figura representada. La misma ubicación del objeto, relieve, pintura o mosaico debe decirnos ya que lo allí representado no es sólo lo que físicamente describe la pieza artística. Debemos interpretarla teniendo en cuenta el lugar en que se encuentra, el público a quien va destinada, la circunstancia temporal en la que ese público la contemplará. Tratándose de una sinagoga, un lugar de culto que puede ser también de reunión para otras actividades, como pueden ser las instructivas y educativas, la rueda del tiempo alrededor del dios sol tiene que ser vista como aludiendo a múltiples ideas, principalmente de carácter religioso, pero también de carácter práctico e instructivo. Ideas religiosas representadas bajo ropajes astrológicos, calendario litúrgico descrito con elementos del calendario agrícola, el Zodíaco de las sinagogas es un exponente de la doble tendencia que veremos también entre los Padres de la Iglesia. Por una parte, exclusión total de las ideas del mundo pagano que reconocía por dioses a los elementos astrales y les atribuía una influencia absoluta sobre el desarrollo de la vida del hombre en este mundo. Por la otra, el uso de aquellas mismas formas y representaciones de los astros, empezando por el sol y la luna, pasando por las doce constelaciones y terminando con las estaciones del círculo anual, todo según los modelos tradicionales del mundo pagano. La figura central del sol presentada bajo el ropaje de Helios, representaba perfectamente la fuerza dominadora del Dios creador. Más que escandalizar a los creyentes judíos, ello les ayudaba a imaginar lo que ya sabían y creían, acostumbrados como estaban a cantar sus alabanzas a Dios con palabras de los Salmos que ya comparaban la potencia universal y la gloria divinas a la figura del sol, imaginando a éste personificado, cabalgando en su carroza por el firmamento, vestido de púrpura e iluminando el 
mundo, radiante como el esposo saliendo de su cámara nupcial ${ }^{17}$. La disposición circular de las constelaciones, de los meses y de las estaciones alrededor del sol era la más perfecta de las expresiones de total dependencia de Dios de todo el mundo creado, de los tiempos sucesivos y repetitivos, de los trabajos del hombre y de su vida entera ${ }^{18}$. Las fiestas litúrgicas, que se repetían anualmente en unas fechas predispuestas por la voluntad incambiable de Dios, quedaban enclavadas entre meses lunares y constelaciones recorridas por el sol durante un año. Y si, además de estas alusiones, el servicio divino de la sinagoga les recordaba a los fieles el del añorado Templo y les impelía a desear la renovación del mismo en un futuro mesiánico que no podía estar lejano, también esto estaba representado en el suelo de la sinagoga. Este, en efecto, supeditaba la figura del circulo astral a la más preeminente del arca santa de la Torá, que les representaba el lugar celestial donde residía la Presencia misma de Dios, la divina shejiná.

Visto con esta perspectiva de múltiple significado, la presencia del Zodíaco en las sinagogas nos revela hasta qué punto los rabinos del tiempo aceptaban el uso de unos cuadros estéticos de origen pagano para expresar la fe israelita en la centralidad de Dios en el universo y para ayudar a los fieles a recordar los principios del orden establecido por los que se desearrollaba su vida litúrgica. Es cierto, por lo demás, que existía en ciertos círculos judíos de aquella misma época, tanto en Palestina como en Mesopotamia, una tendencia al uso de principios y fórmulas astrológicas que hoy parecerían inaceptables. Así lo prueban los textos encontrados en el ábside de la sinagoga de la antigua ciudad de Menois, en el sud del país de Israel (kibbuts Nirim). Se trata de textos mágicos inscritos en pequeñas planchas de metal. En Mesopotamia se han encontrado cantidad de textos mágicos judios de la misma época, por lo general escritos en aramaico en el interior de platos y tazones de cerámica. A propósito de estos hallazgos, junto con otros amuletos judios encontrados en Israel, escribe A. Ovadiah con acierto que todo ello «indica que la frontera entre el judaísmo y las prácticas

\footnotetext{
17 Véase el texto de Midrash RabBah a Números 12: 4, glosando las palabras del Cantar de los Cantares 3:10 y del Salmo 19:6-7.

18 Es bajo esta perspectiva de significado alegórico de la representación del sol en el centro del mundo como figurando «el poder de Dios sobre el universo, el cosmocrátor todopoderoso," que interpreta el zodíaco de Séforis el Prof. Zeev Weiss, descubridor de este mosaico (véase el resumen de ésta y otras interpretaciones del zodíaco en las sinagogas en Bussis TAIT 1997-98).
} 
mágicas y astrológicas era algo borrosa" (Ovadiah 1994: 213). El mismo autor alude también a un texto que se recita en la sinagoga en la vigilia del día conmemorativo de la doble destrucción del Templo, el 9 del mes de $\mathrm{Av}$, en el que se describe a la «hueste celestial llorando y a las constelaciones echando lágrimas" por aquella destrucción (ibid. 215) ${ }^{19}$. Hay que observar, sin embargo, que estas imágenes poéticas no iban de acuerdo con lo que era la pauta en el judaísmo oficial ortodoxo, cuando se expresaban los rabinos con aquel dicho conocido: "No hay mazal en Israel» (Talmud de Babilonia, Shabbath 156a-156b) (ibid. 212-213). La palabra mazal, que lilteralmente significa 'constelación', era usada ya entonces, como hoy día, para indicar 'la suerte', la fortuna casual, ciega, prácticamente independiente de la voluntad de Dios.

En cuanto a la figura del sol, motivo central de la rueda del tiempo en las sinagogas, no hay duda de que su uso no podía haber entrado con demasiada facilidad en la mentalidad judía del tiempo. Parece como si los antiguos residentes de Qumrán, los Esenios de Plinio y de Josefo, y los Terapeutas de Filón de Alejandría, todos ellos grupos disidentes del judaismo centralizado en el culto del Templo de Jerusalén, hubieran influido en la mentalidad de los rabinos posteriores acerca de la importancia del sol como símbolo, si no más, de la centralidad de Dios mismo en el tiempo y en el universo. Todos aquellos grupos disidentes daban una importancia máxima al astro rey, hacia el cual se volvían cuando rezaban. Algunos autores no dudan en ver en eso una manifestación de la influencia directa del culto pagano del dios Helios (Smith 1982). La verdad es que todavía en el siglo II había judíos en Palestina que practicaban una especie de culto al sol, puesto que el Rabino Judá, quien floreció hacia el año 150 d.C, tenía que declarar hereje a quien se atreviese a decir una bendición sobre el sol (Liebermann 1951: 399). En el siglo IV conocemos por Epifanio la existencia de la herejía de los llamados "servidores del sol", los Sampseos o Samseos (de la palabra shemesh, "el sol» en hebreo) que habitaban sobre todo en Perea, al otro lado del Jordán, y en las orillas del Mar Muerto (ibid.: 374). En relación con todo ello podríamos mencionar la curiosa presencia de una "svástica", un conocido símbolo solar de origen oriental, que había sido colocada como emblema

19 Otros textos mágicos, místicos y litúrgicos judios, conteniendo nombres de ángeles y alusiones a los meses, las constelaciones y las estaciones del año personificadas, son mencionados por Roussin (1995: 92-93). 
en el mosaico de la sinagoga de 'Ein Guedi (Fig. 15) en un primer período, tal vez en el siglo III (Barag-Porat-Netzer 1981) ${ }^{20}$. Otra representación del sol es la curiosa cabeza de Helios que aparece entre volutas, sosteniendo un águila que abre sus alas (Fig. 16), en un ángulo conservado del mosaico pavimental de la sinagoga de Yafia, en Galilea occidental (Sukenik 1951; Foerster 1967). Temáticamente, esos detalles tienen ciertamente algo que ver con el uso de la figura del sol en la rueda del tiempo.

Por lo que se refiere a la las representaciones de las constelaciones, no hay que olvidar la relación que ya Filón de Alejandría veía entre ellas y las doce piedras preciosas que llevaba el sumo sacerdote sobre su pecho en el efod (Ex XXVIII, 9-12). Evidentemente, el número sagrado de doce piederas representando las doce tribus de israel le daba ocasión para relacionarlas con las doce constelaciones ${ }^{21}$. Por ello, nadie puede negar que las representaciones de las constelaciones en las sinagogas alrededor del dios sol, además de estar relacionadas con los meses del año judío no podían menos que evocar en la mente de los fieles judíos las doce tribus de Israel entorno a su Dios. Será por ello que en la sinagoga de Yafia, los doce medallones entrecruzados que forman la rueda (Fig. 17) no contenían representaciones de las constelaciones, como en las demás sinagogas descritas, sino figuras simbólicas de las doce tribus de Israel. De estas figuras se conservan sólo en parte las de un búfalo con el final de la palabra

20 Por lo demás, resulta curioso verlo tambén esculpido sobre el dintel de la entrada principal de la iglesia sur de Shivta, la antigua Sobata de los Nabateos, quienes habian te. nido también, por lo que parece, una especial veneración por el astro rey (LEVY 1996: 118-121).

${ }^{21}$ De VITA Mosis II, 122-123: “Porque del mismo modo que las piedras son iguales entre ellas, así lo son también los dos hemisferios, el que está por encima y el que está por debajo de la tierra... Un testimonio semejante se da por su color, puesto que el cielo entero se nos presenta a la vista como la esmeralda. Además, sobre cada una de las piedras tenía que grabarse uno de los seis nombres, puesto que cada uno de los dos hemisferios divide el Zodiaco [ton zoophoron] en dos y se atribuye seis de los signos. En segundo lugar, las piedras sobre el pecho, que son de colores diversos y se dividen en cuatro filas de tres, ¿qué otra cosa pueden significar sino el círculo del Zodíaco [tou zodiakou kyklou]? Puesto que, si dividimos el circulo en cuatro partes, forma con tres signos en cada una las estaciones del año: primavera, verano, otoño e invierno. En cada una, la transición está determinada por tres de los signos, y se nos da a conocer por las vueltas que da el sol, según una ley matemática, permanente, inmutable, y realmente divina. Por lo tanto, también ellos fueron fijados en lo que bien se llama el lugar de la razón [to... deontos logeio], puesto que un principio racional, ordenado y firmemente establecido, crea las transiciones y las estaciones del año (texto griego tomado de COLSON 1925: 508). 


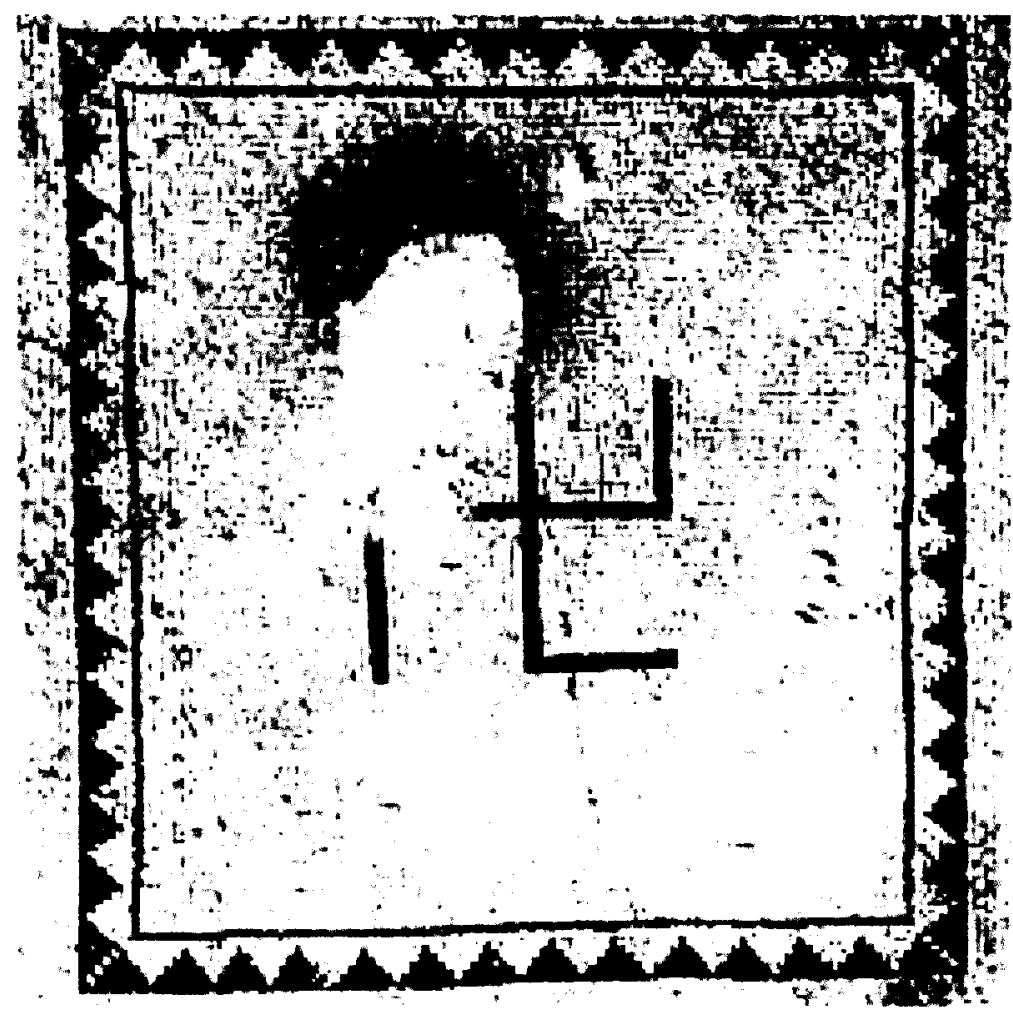

Figura 15. Svástica. Sinagoga de 'Ein Guedi (HaCHLILI 1988: pl. 96b).

[Ef]raim (Fig. 18), y de un buey, que representaría Manasés ${ }^{22}$ Ignoramos cuál sería la decoración en el interior de esta banda circular, semejante a la del Zodíaco en otras sinagogas ${ }^{23}$, pero normalmente se supone que contendría igualmente la representación del sol. No faltan, por otra parte, escritos judíos antiguos que atribuyen los nombres de las doce constelaciones a las doce tribus, como el texto de un cierto historiador judío llamado Asaf, conservado sólo en un fragmento siríaco (Goodenough 1988: 150).

22 BARAG (1992: 593) hace observar que en Midrash Rabba 82 el buey es símbolo de Efraim y el búfalo lo es de Manasés.

23 Goodenough no dudaba en ver también en Yafia una rueda del Zodíaco (vol. I, 216-218). 


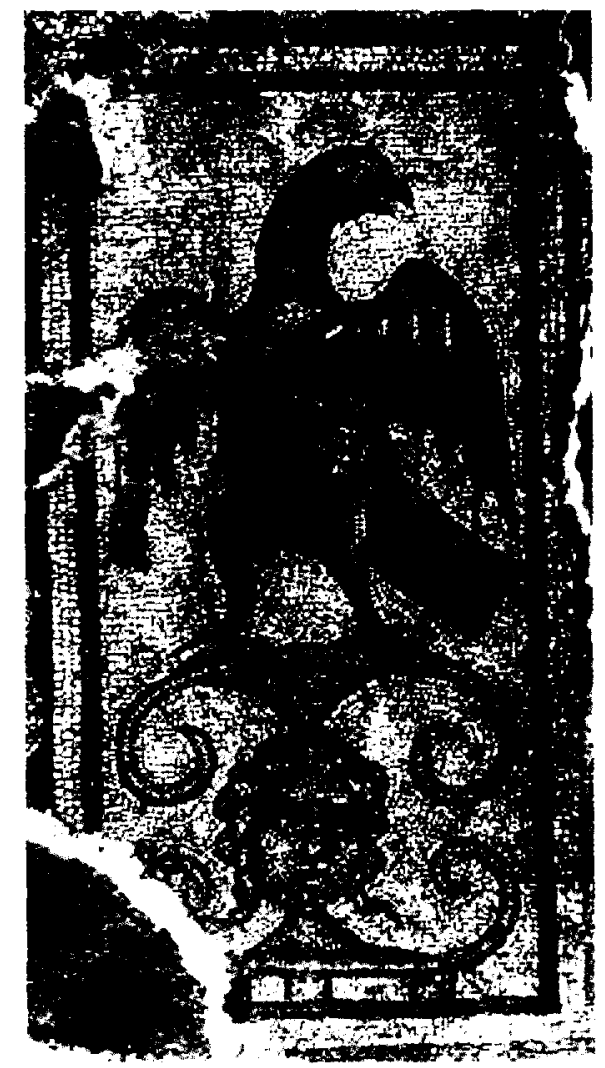

Figura 16. Aguila y Sol. Sinagoga de Yafia (Barag 1993: 660).

Resumiendo todo lo dicho, uno no puede dejar de subrayar el carácter pagano de la decoración de las sinagogas con la rueda del Zodíaco, sea cual fuera la interpretación precisa que se le quiera dar. Incluso admitiendo el uso del Zodíaco como calendario litúrgico o como representando el hejal del Templo, la presentación de cada una de las constelaciones está obviamente basada en sus precedentes clásicos, paganos. Pero no debemos suponer que esta influencia cultural pagana se redujese exclusivamente a la expresión artistica. Podemos aceptar igualmente, sin miedo a equivocarnos, una influencia de pensamiento, por lo menos en el modo de imaginar la jerarquía en el orden divino del universo: la centralidad de Dios expresada como la función central del sol en el universo. La sumisión de los hombres a la constante voluntad del Dios en el transcurso de los acontecimientos de su vida y en los diversos cambios del tiem- 


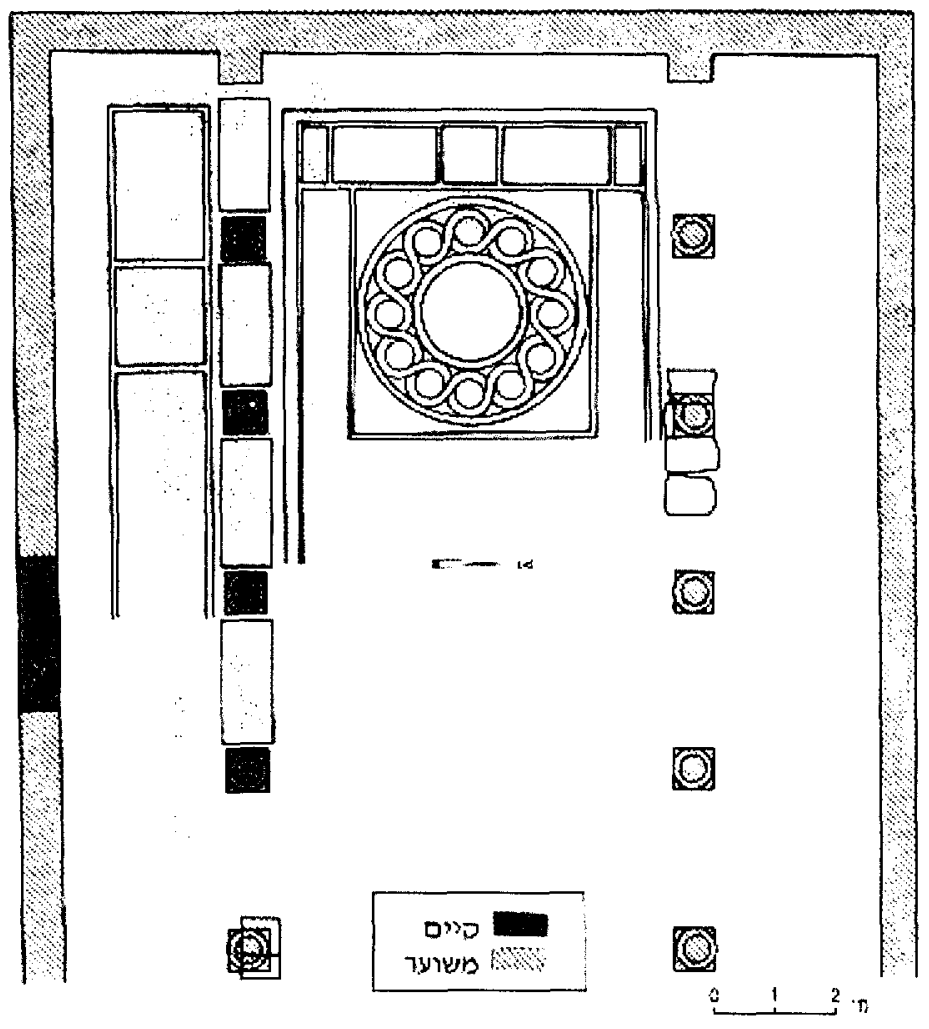

Figura 17. Plano de la sinagoga de Yafia (Barag 1993: 659).

po, era expresada con la rueda de las constelaciones y los meses. La importancia y el orden de las fiestas del año litúrgico, fiestas eminentemente agrícolas, eran expresados en el modo de colocar las figuras alegóricas de las cuatro estaciones alrededor de las constelaciones y los meses ${ }^{24}$. Por lo demás, esta conjunción de elementos paganos de la

24 Filón de Alejandría menciona explicitamente esta correspondencia entre constelaciones y estaciones del año: «En cada estación del año el sol completa su curso a través de tres signos zodiacales... Por ejemplo, la primavera (consiste) en Aries, Taurus, Gemini, y en el verano tenemos Cáncer, Leo, Virgo, en el otoño Libra, Scorpio, Sagitarius, y en el invierno Capricornium, Aquarius, Pisces... (Questions and Answers on Exodus, Colson 1925: 125-126). Hay que hacer notar, sin embargo, que, tanto en Huseifa como en Naarán y en Bet Alfa, no existe una correspondencia exacta entre los signos del Zodiaco y las respectivas estaciones 


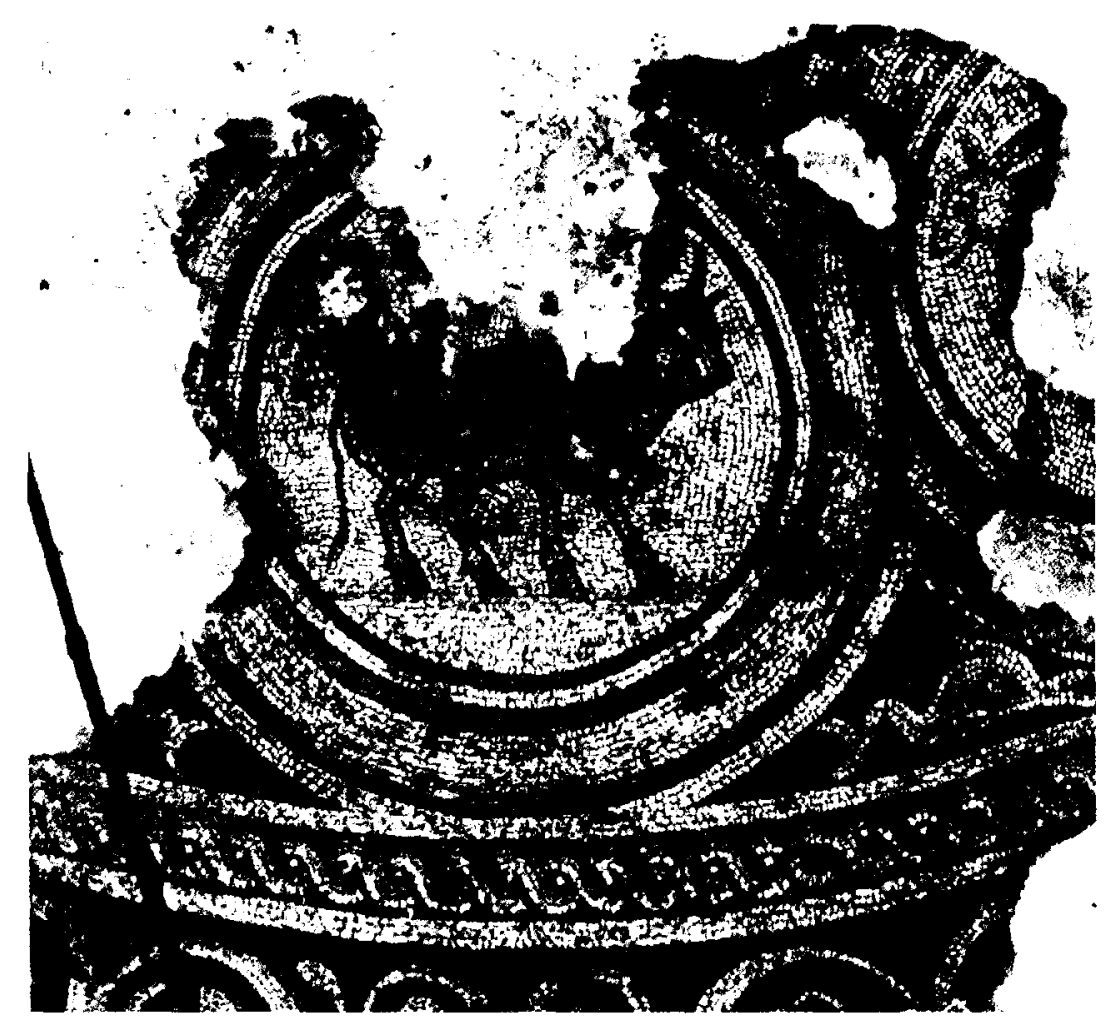

Figura 18. Búfalo. Sinagoga de Yafia (Barag 1993: 660).

decoración y de su aplicación a la religión judía daría paso libre a una cierta variedad de lectura y comentario por parte de cada grupo y de cada maestro en las sinagogas.

\section{Sol, luna, constelaciones, meses y estaciones en la perspectiva cristiana}

A pesar de que en la época y región que nos ocupa (es decir, entre los siglos IV al VII en las provincias orientales del imperio), el tema del

del año, cosa extraña tratándose de un calendario. Tal particularidad, dice Guidoni (1983:253), no puede ser atribuida a error o ignorancia. 
Zodíaco propiamente dicho no aparece en ningún ambiente cristiano, el hecho de que el tema fuese tratado por algunos Padres de la Iglesia nos ha llevado a añadir algunas de las ideas que ellos emitieron acerca del Zodíaco en general y del simbolismo atribuido por ellos a elementos tan centrales como el sol y la luna. No olvidemos que el único mosaico cristiano palestinenese paralelo a los Zodíacos sinagogales, el del monasterio de Doña María en Bet Sheán-Escitópolis, representa las figuras de los doce meses en una rueda radiada alrededor de las figuras centrales del sol y de la luna personificados (Fig.19). Y es también en una tumba cristiana de Bet Sheán (El Hammam) donde aparece otra reproducción de los doce meses en mosaico (Fig. 20). Pero, dado que el tema de la rueda del Zodíaco aparece también, unos siglos más tarde, en los mosaicos de algunas iglesias del período románico en Europa, no se puede rechazar la idea de que exista una cierta relación entre la interpretación judía del tema del Zodíaco en aquella misma época y el significado que le daban también los cristianos a esta rueda del tiempo. Por eso, la aportación de los Padres a la interpretación del tema del Zodíaco o de alguno de sus elementos, podrá ser también de alguna utilidad.

Empezando por un texto de Basilio el Grande en sus «Homilías sobre el Hexamerón", podemos apreciar su perfecto conocimiento del sistema del calendario lunar y del calendario solar. El primero, usado por los hebreos y los griegos antiguos, lo marcan las doce veces que la luna ha acabado su curso, después de lo cual hay que intercalar a menudo un mes para completar el curso de las estaciones. El segundo lo marca «el retorno del sol, que por su propio movimiento vuelve de un signo (del Zodíaco) al mismo signo" ${ }^{25}$. Tal vez lo más importante para nosotros en este texto es la observación que hace Basilio acerca del sol, de que éste hace el recorrido de los doce signos «por su propio movimiento". De este modo se pone de relieve la supremacía del sol con respecto a todos los demás astros, y que lo asemeja al mismo Dios en su función central en la creación. Ya Clemente de Alejandria había hablado de tal situación central del sol al comparar a éste y a los planetas con el candelabro de los siete brazos, a semejanza de Flavio Josefo: «... también el sol, como el candelabro, está colocado en medio de los demás (astros) errantes, y

25 El texto griego dice literalmente: “...he apo tou autou semeiou to auto semeion kata ten oikeian kinesin tou heliou apokatastasis» (BASILE LE GRAND, Homélies sur l'Hexameron, ed. Giet 1968, p. 370). 


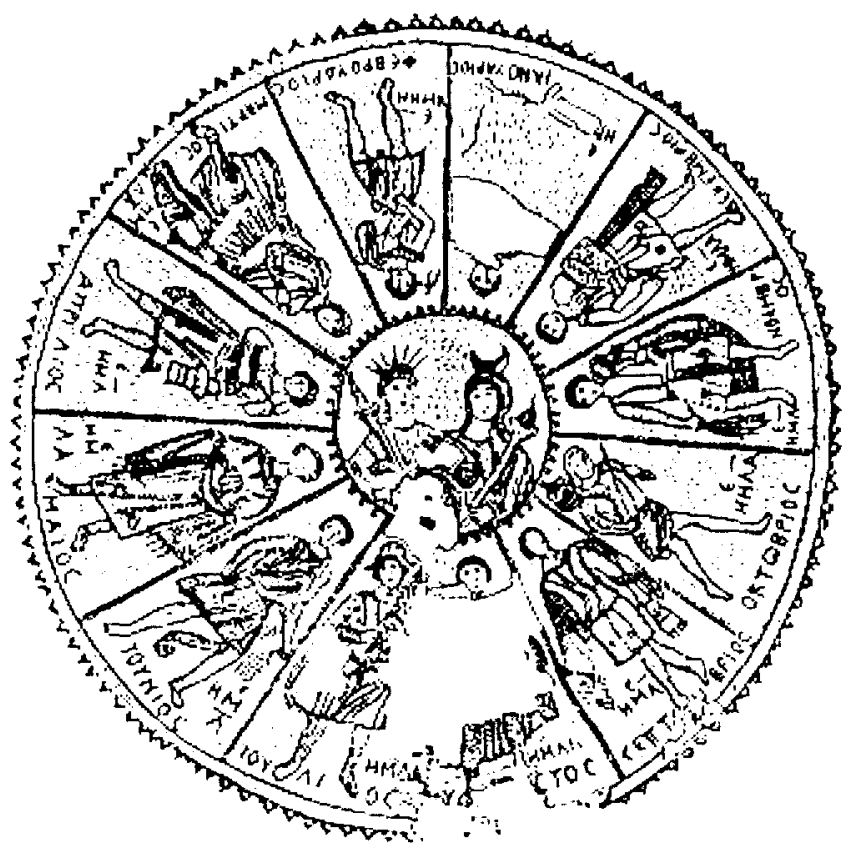

Figura 19. Rueda del tiempo. Monasterio de Doña María.

Bet-Sheán - Escitópolis (Hachlili 1988: 122, fig. 7).

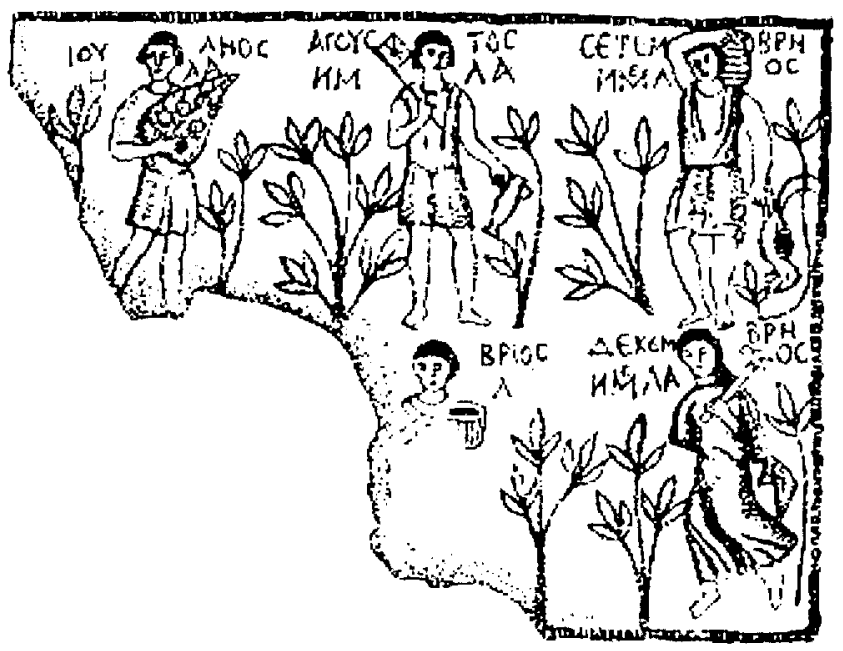

Figura 20. Los meses. Tumba cristiana de El Hammam. Bet-Sheán - Escitópolis (Hachlili 1988: 122, fig. 7). 
les da la luz a los que están por encima y a los que están por abajo, como con una divina música" ${ }^{26}$. Clemente, naturalmente, habia heredado de los pitagóricos la visión de la centralidad e inmanencia de Dios en el universo, a quien describían, según él mismo, con palabras que en gran parte podían aplicarse simplemente al sol ${ }^{27}$.

Esta centralidad e independencia del sol la observa también Gregorio de Nysa, quien, sin embargo, se da cuenta también de la debilidad que le causan al gran astro los eclipses de la luna: ... «los doctos y los sabios observan el movimiento concordante y ajustado de los planetas, el circulo del llamado Zodíaco ${ }^{28}$... la multiforme mutación de la luna, y el movimiento del sol en medio de los polos, el cual, lleno como está de su propia luz, coronado con sus propios rayos en círculo y abarcándolo todo con su potencia iluminadora, desfallece a veces cuando el llamado cuerpo lunar lo cubre y le hace sombra" ${ }^{29}$. O sea, el sol, a pesar de su importancia y de su fuerza no pasa de ser una creatura como las demás. No es dios. Los teólogos cristianos debían insistir en el aspecto secundario del sol. Se ve claro en el diálogo imaginado por Zacarías de Mytilene, originario de Gaza, en el que Ammonio declara al cristiano su creencia de que «Dios es padre y sol (Gr. pater kai helios) de cada uno. Le pregunta el cristiano: ¿Tú crees que Dios es el sol? Ammonio: Así lo creo yo, a no ser que demuestres lo contrario.... ${ }^{30}$.

La visión cristiana del mundo estaba, a fin de cuentas, bien lejos de la elevación hecha por los paganos del sol a la categoría divina, y del

26 Clemente prosigue diciendo que "el candelabro (la Menorá), es un símbolo enigmatico de (la cruz de) Cristo. No sólo por su forma. sino por el hecho de que de muchas y diversas maneras les manda luz a aquellos que en él creen, esperan, y le contemplan" (CLEMENTE DE ALEJANdRiA, Strommata V, V, PG 9, 59-62). Es probablemente con este paralelo Cruz Menorá que hay que interpretar la aparición de este último símbolo (aunque algo estilizado) entre dos cruces al final de una inscripción sepulcral en el pavimento de la iglesia bizantina de S. Teodoro, en la ciudad de Avdat (antigua Oboda nabatea), en el desierto del Néguev, al sur de Israel.

${ }_{27}$ "Dios, dicen (los pitagóricos), es único. No está, como algunos suponen, fuera del sistema del universo, sino totalmente dentro de él, existiendo eternamente, maestro de su propia actividad, iluminador de todos los cuerpos celestiales ( $\mathrm{Gr}$. apanton en ourano phoster), padre de todo espíritu y animación del ciclo entero, movimiento de todas las cosas" (CLEMENT AlEX., Le protreptique, Sources Chrétiennes, Paris, 1949, p. 137).

28 Lit. zoophoron.

29 Gregorio de NYSA, Contra Eunomium, Lib. XII, PG 45: 933.

3o Zacarias de Mytilene, Disputatio de Mundi Opificio, PG 85: $1044 \mathrm{ff}$. 
uso que hacian los judíos de su representación entre las constelaciones, tanto si lo veían como centro natural del universo como si lo aceptaban como símbolo de Dios mismo. La tradición cristiana, ya desde la primera generación, había transformado en figuras sensibles de realidades transcendentes aquellos elementos naturales que evocaban, por su función en el universo, el poder de Dios, y sobre todo la figura central de Cristo en la redención. Es así que, ya entrado el siglo VII, Atanasio, un monje del Sinaí, nos parangona la función natural del sol y de la luna en el universo creado con la función espiritual de Cristo y su Iglesia entre los redimidos. Los textos son muy explícitos: «En el firmamento, Helios tiene el primer lugar y preside la danza. De un modo semejante, Cristo, que es el sol espiritual, está colocado en el cielo por encima de todos los dominios y poderes, porque es la puerta y el maestro que guía hacia el Padre. Sobre la tierra, empero, a donde descendió en humildad tomando sobre sí la forma de siervo, transmitió su primacía de lugar a su cuerpo, que es la Iglesia, y lo hizo en el sacramento del bautismo. Ahora bien, Selene (la luna) da luz a los hombres sobre la tierra, y por ella me refiero a la Iglesia, puesto que Selene tiene potestad sobre todas las aguas, y la Iglesia tiene poder sobre el Espíritu Santo, que Cristo confió y regaló a su Iglesia, a fin de que nos dé a luz en nuestro renovado nacimiento" ${ }^{31}$.

Es también el monje Anastasio del Sinaí quien, en un arrebato de poesía ante el "misterio» del sol y de la luna, nos describe a la Iglesia bajo la figura de la divina Selene, la luna, consorte de Cristo-Sol ${ }^{32}$. En poemas como éste vemos hasta qué punto la visión pagana del mundo era todavía utilizada como soporte para la fe cristiana, que la sublimaba sin destruirla ni paliarla:

\footnotetext{
“No desaparezcas jamás en la oscuridad de una luna menguante, Selene, perpetuamente reluciente.

llumina nuestro camino a través del sentido divinamente escondido de las Escrituras.

No ceses,

Tú, consorte y compañera de camino de Cristo el sol,

Quien, en su calidad de novio, te viste de luz,
}

31 Anastasius Sinaita, Hexamerón, 5, PG 89: $113 \mathrm{c}$-d.

32 Recordemos que una de las más antiguas figuras pictóricas de Jesucristo, en la necrópolis del Vaticano, lo representa en mosaico sobre muro bajo la evidente figura del dios Helios, con cabeza radiada y cabalgando sobre carroza. 


\section{No ceses}

de enviarnos aquellos rayos que tomaron de él la brillantez,

A fin de que, de él, pero por ti,

Pueda dar luz a las estrellas

$Y$ pegarles fuego,

por ti, para ti» ${ }^{33}$.

El P. Rahner, de quien recogimos el texto precedente, dice de él con razón: "Aquí está la santificación cristiana de aquel amor por el mundo de los cuerpos celestiales que es tan típicamente griego, y en aquella santificación está la esencia misma del misterio eclesial del sol y la luna" (Rahner 1963: 175).

Creo que es con esta mentalidad y bajo esta perspectiva que podemos contemplar el mencionado mosaico de los meses del monasterio bizantino llamado de Doña María, que estaba situado sobre la cumbre del tel de Bet Sheán-Escitópolis (Fig. 19) ${ }^{34}$. El sol y la luna, Helios y Selene, aparecen en el medallón central personificados, ataviados sus bustos con los respectivos atributos; alrededor de ellos, en forma radial, los doce meses del año, identificados por sus respectivos nombres latinos en caracteres griegos y por las labores agrícolas que se practican en cada uno de ellos. A diferencia de los Zodíacos de las sinagogas, no aparecen aquí las constelaciones. Pero la disposición de toda la rueda del tiempo en el centro del pavimento de la sala (o patio interior) es tan semejante, que no dudamos de que los mosaístas se hayan inspirado en la decoración de las sinagogas en las que aparece el Zodíaco. Es evidente que la intención primera de los mosaístas o de los que les invitaron a ejecutar su trabajo era la de producir un calendario solar agrícola, muy natural en una región eminentemente agrícola como la de Bet Sheán. Por otra parte, la elección y presentación de las figuras centrales dejaba entrever el fondo pagano en que se habían inspirado. También eran de origen pagano las figuras de los meses alrededor del medallón central, y los vemos en Oriente, en Antioquía, en el siglo III (Lassus 1975: 334). Pero el contexto religioso, monástico, donde estaba situada toda la decoración, favorecía una interpretación cristiana de los elementos centrales, el sol y la luna, que si no eran figuras simbólicas de Cristo y de la Iglesia, por lo menos evocarían la centralidad de ellas en el orden cós-

Ibid.: $1076 \mathrm{c}-\mathrm{d}$.

34 Fitzgerald 1931: 62-70, PI. I; Fitzgerald 1939; LIMC, Menses, 22. Véase en Parrish 1993 un estudio comparativo de los meses y bibliografia. 
mico. No olvidemos la función primordial de bóveda celestial de las decoraciones circulares y cuadradas (Tomasevic 1995). Ello es evidente en ambiente cristiano, como las bóvedas de los bautisterios de Ravenna, que son de la misma época que nuestro mosaico de Bet Sheán, y en las que las figuras de los meses fueron cambiadas por las de los doce apóstles como hace notar también Lassus (ibid.). En Bet Sheán, a semejanza de las sinagogas, la rueda del tiempo tiene la función de pavimento, pero ello no quiere decir que los responsables de su ejecución no hayan tenido muy presente aquella proyección que representaba de la bóveda del cielo sobre la tierra, de la supeditación de la vida del hombre a la de Dios, y de la centralidad radical de éste en el orden cósmico y universal. Cabe recordar aquí que fue también en los alrededores de Bet Sheán, en El Hammam, donde se descubrió el mosaico pavimental de una tumba bizantina representando los doce meses personificados, identificados también por sus nombres latinos en caracteres griegos y ostentando los atributos de las labores agrícolas relativas a cada uno de ellos (Fig. 20). Además de evocar la temporalidad de la vida del hombre, los meses, que aquí aparecen representados entre plantas, parecen indicar también la abundancia de fruto de que va a gozar el hombre en el otro mundo según lo que haya trabajado en el presente durante su vida.

En el mosaico de la rueda del tiempo de Bet Sheán, con los meses alrededor de Helios y Selene, no figuran las figuras de las cuatro estaciones. El círculo de los meses no está encuadrado, y por lo tanto no hay ángulos que decorar. A su alrededor tenemos una decoración general de tipo geométrico, con medallones que contienen figuras de animales. Pero el tema de las estaciones personificadas existe en numerosos mosaicos cristianos de Oriente, y sobre todo en iglesias bizantinas de Jordania, que tienen también los meses como motivo principal. Las publicadas son las siguientes:

1. Gerasa, capilla de Elías, María y Soreg ${ }^{35}$; la capilla de la catedral, mosaico hoy destruido ${ }^{36}$; e iglesia de San Juan, también destruido ${ }^{37}$.

2. Qabr Hiram. Mosaico del AD $575^{38}$. Umm Ar-Rasas. Iglesia del obispo Sergio, con estaciones en los ángulos, de las que se con-

\footnotetext{
Saller-BagatTI 1949: pl. 46-47; LIMC, "Menses".

LIMC, “Menses", 24

$\angle I M C$, "Menses", 23.

LIMC, "Menses", 4.
} 
serva sólo una. Esta sostiene una cornucopia de la que emergen ramos de vid. ${ }^{39}$. Hay que recordar aquí que en Mádaba aparecen también las estaciones en los ángulos de dos ambientes profanos (arriba, p. 147).

3. Monte Nebo (Khirbet al-Mukhayyat). Las cuatro estaciones, iglesia del sacerdote Jorge ${ }^{40}$. Fechado en AD 536.

4. Deir es Sleib. Mosaico con representaciones de estaciones y animales ${ }^{41}$.

5. Petra. Mosaico con bustos de la primavera (Fig. 21) y del verano ${ }^{42}$, además de Oceáno ${ }^{43}$, en la iglesia recientemente excavada.

No las estaciones pero sí caras y máscaras se ven en cuatro ángulos de varios mosaicos cristianos de Mádaba: Iglesia Catedral, con cabezas entre hojas en dos de los ángulos expuestos del cuadro (Piccirillo 1993:116, fig. 106). Iglesia de los Apóstoles, con cabezas entre hojas en dos de los ángulos del cuadro (ibid. 99, fig. 81; 102, fig. 84; 107, figs. 93, 95). Iglesia del diácono Tomás, con máscaras en los ángulos (ibid., fotos 267, 268).

Además de estas representaciones de las estaciones en mosaicos de iglesias, tenemos que mencionar aquí también las que figuran en relieve en un sarcófago de plomo cristiano descubierto en los terrenos del Kibbuts Nirim, donde estaba situada la ciudad bizantina de Menois (Figueras 1996: 271-274). No hay duda de que el sarcófago fue utilizado para una sepultura cristiana, pues tiene también cruces como decoración, además de las pequeñas edículas en donde aparecen, de pie, las estaciones (Rahmani 1996). Aunque en otro contexto, vemos una vez más el uso cristiano de estas representaciones paganas de las estaciones, que indudablemente estaban vinculadas al pensamiento de la temporalidad de la vida. Es asi que se interpreta su uso tan habitual en los relieves de los clásicos sarcófagos de mármol.

39 PiCCIRILlo 1993: 71, figs. 35, 41-42; 207, fig. 332.

40 BuschHAusen 1986: Abb. 74, y en color en p. 228, 15 'primavera'; SAller-BAGatTI 1949: 38-39, 49-55, 172-180.

4 DONCEEL-VOUTTE 1988: 61-69.

42 ACOR 1993: 69.

43 Véase la reproducción y el comentario de esta figura en el articulo anterior. 


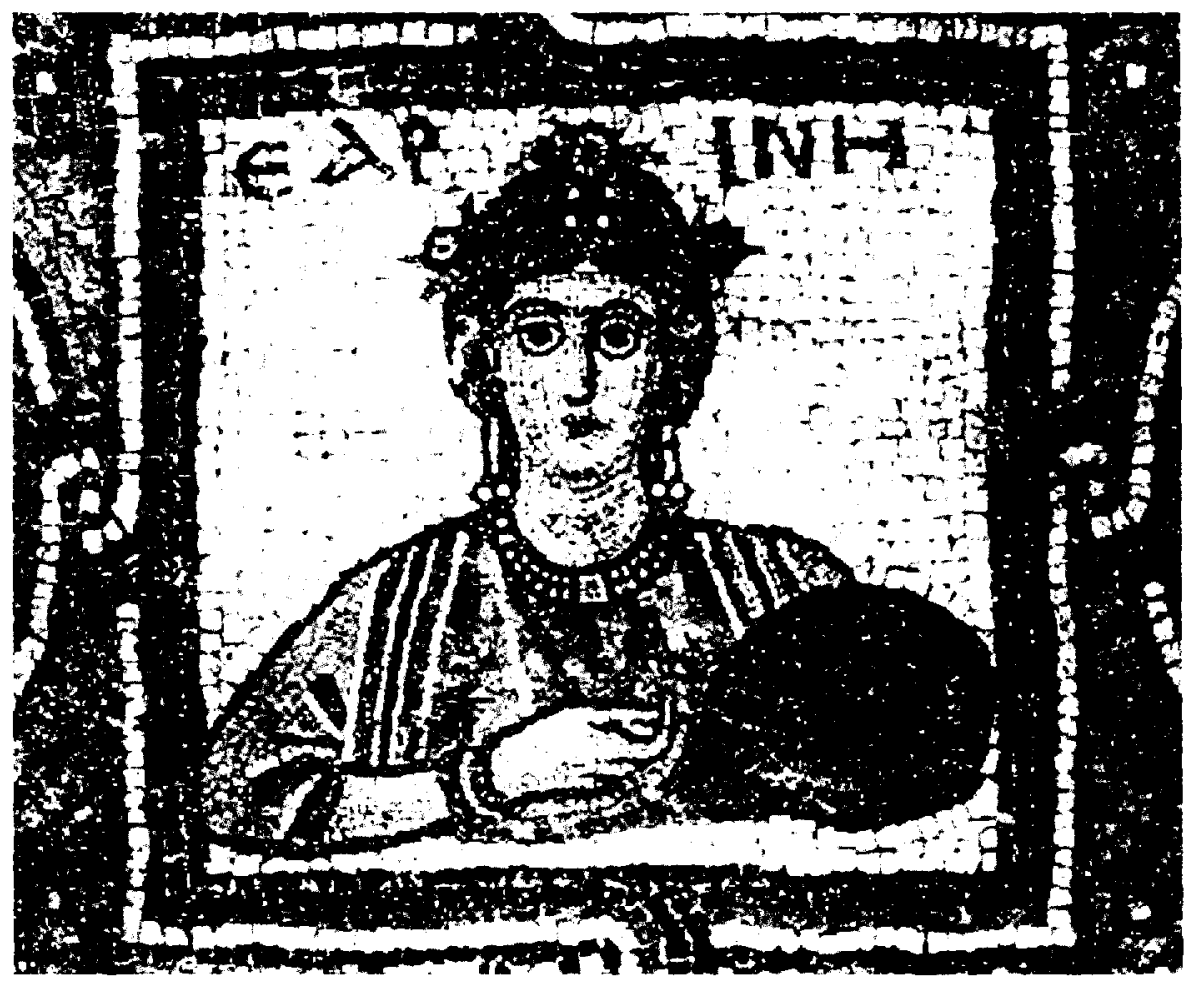

Figura 21. Primavera. Iglesia de Petra (Acor 1993: frontispicio).

\section{RESUMEN}

La aparición de la rueda del Zodíaco como motivo principal en varias de las sinagogas de la Palestina en la época del Talmud es y será por mucho tiempo tema de discusión entre los estudiosos de la historia del arte judío. Es una intrusión pagana demasiado evidente en el contexto cultural de la religión aparentemente más monoteista y conservadora para dejarla de lado con soluciones fáciles. La más sencilla es la de aquellos que no ven en las figuras del Zodíaco y su centro solar más que un calendario, agrícola o litúrgico. Pero el hecho de que, ya en el mismo período del uso de tales pavimentos, se diera eventualmente oposición a tal presentación de tradición pagana del tiempo (como vemos por la sustitución de un Zodíaco por un pavimento geométrico en Horvat Susiya, o por la supresión de la figura del dios $\mathrm{He}$ - 


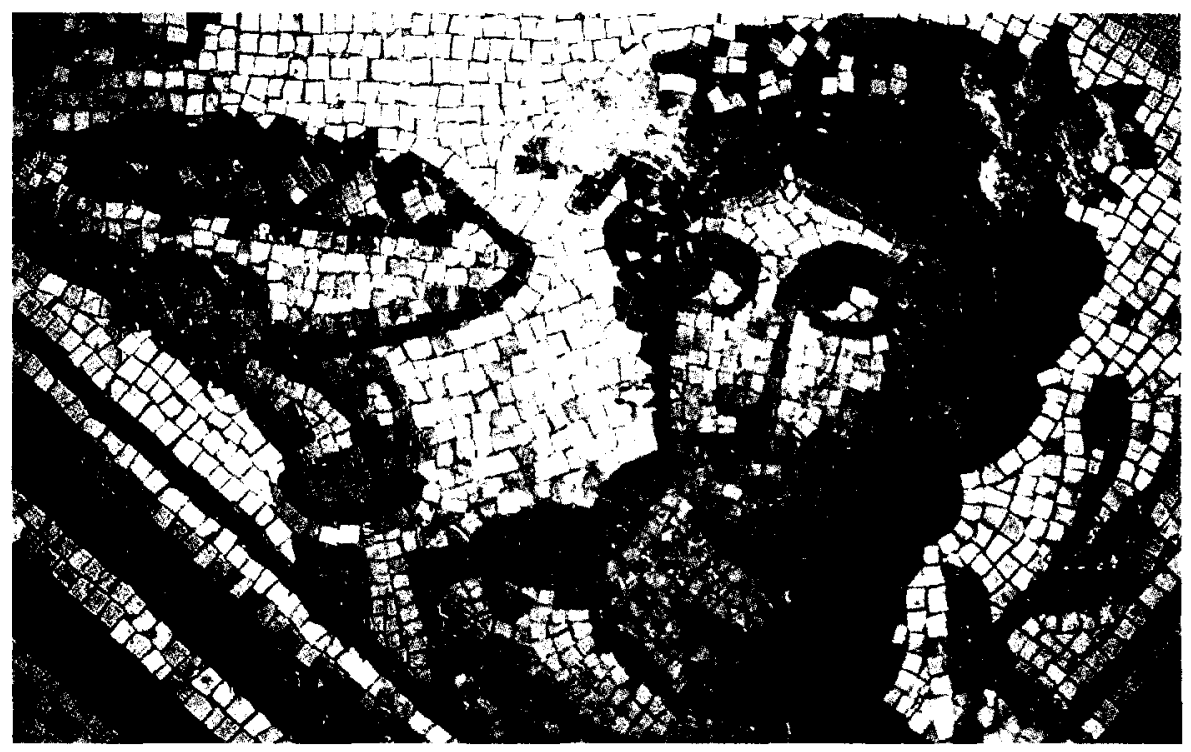

Figura 22. Nisán. Sinagoga de Hammath Tiberias (Foto I. GRINBERG).

lios en Séforis), nos obliga a admitir que aquellas figuras tradicionales paganas eran usadas para servir muy directamente a la causa religiosa judía. No debemos rechazar la idea de que la decoración del pavimento sinagogal pudiera servir de calendario, litúrgico o no, para admitir que aquella bóveda celestial proyectada en el suelo pudiera también estar destinada a hacer sentir más intensamente la presencia divina en la vida cotidiana, y tener conciencia de la total dependencia del mundo y sus mutaciones de aquel Ser divino que rige el universo entero. La ortodoxia judía, que no admitía la influencia directa de las constelaciones sobre la vida del hombre, como hacían los paganos, sí podía presentarlas como dependiendo totalmente de aquel Ser central, reproducido en la forma tradicional del sol que todo lo ilumina y que a todo da vida. Por otra parte, viendo cómo se identificaba a veces las constelaciones con las tribus de Israel, el paso del astro divino por cada uno de ellas acrecenta a nivel de pueblo aquella dependencia y aquella presencia. Con estos pensamientos de fondo, aquella presentación aparentemente pagana animaba a mantener la fe en un orden cósmico basado en la centralidad de Dios, y en una relación totalmente particular entre el pueblo de Israel y su Dios. No podemos prescindir 
de intentar una lectura múltiple del tema del Zodíaco y sus componentes en los mosaicos sinagogales si no queremos quedarnos cortos en la comprensión de su rico significado.

En cuanto al uso cristiano del tema, ciertamente más prudente que el judío en el mismo contexto geográfico y temporal, la literatura patrística parece ofrecernos la llave para ver cómo las figuras del sol y de la luna se convierten en simbolos de Cristo y su Iglesia, por quienes los fieles son iluminados y tienen vida. No se reproduce el Zodíaco en ningún caso, pero sí una vez la rueda del tiempo con los doce meses del año alrededor del sol y de la luna, y varias veces las estaciones del año. Naturalmente que todos esos temas son variaciones del motivo normal en los pavimentos de las iglesias, el mundo real, la naturaleza, las creaturas, la continuación de la vida, en fin, el papel desarrollado por la creación en el orden cósmico.

\section{BIBLIOGRAFÍA}

ACOR (1993) = ACOR: The First 25 Years. The American Center of Oriental Research: 1968-1993, Amman.

AvI-YONAH, M. (1933): "A Sixth-Century Synagogue at 'Isfiya", Quart. Depart. Antiquit. Palestine 3: 118-131.

- (1968): "The Caesarea Inscription of the Twenty Four Priestly Courses", en The Teachers Yoke Studies in Memory of Henry Trantham, Dallas: 46-57.

- (1981): "Le symbolisme du Zodique dans l'art judéo-byzantine", en M. Avi-YonAh, 1981, Art in Ancient Palestine (trabajos reeditados por H. Katzenstein y Y. Tsafrir), Jerusalem: 396-397.

- (1993): "Husifah", en STERN 1993/2: 637-638.

ANRW = Aufsteig und Niedergang der Römischen Welt, Berlin-New York.

BALTY, J. (1973): «Mosaïque de Gé et des Saisons à Apamée», Syria 50: 311-347, pls. XVXVIII.

- (1981): "La mosaïque antique au Proche-Orient, I. Des origines à la Tetrarchie", en ANRW II, 12, Berlin-New York: 347-429.

BARAG, D. (1993): "Jafia", en STERn 1993/2: 659-660.

Barag, D.; Porat, Y. and Netzer, E. (1981): “The Synagogue at 'En-Gedi», en Levine, L. I. (ed.), Ancient Synagogues Revealed, Jerusalem: 116-119.

BLAZQUEZ J. M. (1981): "Las pinturas helenísticas de Qusayr 'Amra (Jordania) y sus fuentes", Archivo Español de Arqueologia 54: 157-190.

Buschiausen, H. (1986), Byzantinische Mosaiken aus Jordanien, Wien.

Bussis TAIT, L. (1997/98): "Symposium Held in Conjuction with Sepphoris Mosaic Exhibition", Jewish Heritage Report 1: 24-26.

CHEHAB, M. (1958): Mosaïques du Liban, Paris.

CHIAT, M. J. (1980): "Synagogues and Churches in Byzantine Beit Shean", Journal of Jewish Art 7: 6-24.

Colson, F. H. (1925): Philo, vol. VI, Cambridge.

DANIÉLOU, J. (1953): “La symbolique cosmique du temple de Jérusalem», en Symbolique cosmique et monuments religieux (Catalogue de l'exposition au Musée Guimet), Paris: 61-64). 
DONCEel-Voùte, P. (1988): Les pavements des églises byzantines de Syrie et du Liban, Louvain-la-Neuve.

DOTHAN, M. (1968): «The Synagogue of Hammath-Tiberias", Qad 1: 116-123 (en hebreo).

- (1983): Hammath Tiberias: Early Synagogues and the Hellenistic and Roman Remains, Jerusalem.

- (1993): “Hammath Tiberias", en STERN 1993/2: 573-577.

Figueras, P. (1996): “New Inscriptions from the Negev", Liber Annuus 46: 265-284, pls. 56.

Fitzgerald, G. M. (1931): «Excavations at Beth-Shan in 1930", Palestine Exploration Fund Quarterly Statement 1931: 59-70, PI. I-VI.

- (1939): A Sixth Century Monastery at Beth-Shan, Philadelphia.

FoERSTER, G. (1967): "On the Mosaic of Japhia Synagogue", Yediot 31:218-224 (en hebreo). - (1993): "Beth-Shean at the Foot of the Mound", en STERN 1993/1: 223-235.

GIET, S. (ed.) (1968): Basile de Cesarée, Homélies sur l'Héxameron, VI, 5, 2a ed., Paris.

GLUECK, N. (1952): "The Zodiac of Kh. Et-Tannur", Bulletin of the American Schools of Oriental Research, 126: 5-10.

Goodenough, E. R. (1953-1968): Jewish Symbols in the Greco-Roman Period, 13 vols., Princeton.

- (1988): Jewish Symbols in the Greco-Roman Period (Abridged Edition, edited by J. Neusner), Princeton.

Grabar, A. (1980): Christian Iconography-A Study of Its Origins, London.

- (1983): "Quelques observations sur une mosaïque de pavement perdue", en Mosaïques, Recueil d'Hommages à Henri Stern, Paris: 189-194.

Gutman, S.; Netzer, E.; Yeivin, Z. (1978): “Khirbet Susiya”, en Avi-Yonah-Stern 1978: 1124-1128.

HACHLILI, R. (1977): "The Zodiac in Ancient Jewish Art: Representation and Significance",

Bulletin of the American Schools of Oriental Research 228: 61-77.

- (1988): Ancient Jewish Art and Archaeology in the Land of Israel, Leiden.

- (1997): "Aspects of Similartiy and Diversity in the Architecture and Art of Ancient Synagogues in the Land of Israel», Zeitschrift des Deutschen Palästina-Vereins 113: $92-115$.

HUSKINSON, J. (1974): “Some Pagan Mythological Figures and their Significance in Early Christian Art", Papers of the British School at Rome 42: 68-97.

Kraeling C. (1956): The Excavations at Dura Europos. Final Report VIII. Part One. The Synagogue, New Haven.

LASSUS, J. (1975): "La mosaïque romaine. Organisation des surfaces", La mosaïque gréco-romaine, 11 , Paris.

LeHMANN, K. (1945): "The Dome of Heaven", The Art Bulletin 27: 1-27.

LEVI, D. (1941): "The Allegories of the Months in Classical Art", The Art Bulletin 23: 251-291.

LEVINE L. I. (1981): "The Inscription at En-Gedi», in LeVINE L.I. ed., 1981, Ancient Synagogues Revealed, Jerusalem: 140-142.

LEVY, U. (1996): Die Nabatäer, Versunkene Kultur am Rande des Heiligen Landes, Stuttgart.

LIEBERMAN, S. (1951): "Light on the Cave Scrolls from Rabbinic Sources", Proceedings of the American Academy of Jewish Research 20: 395-404.

LiNG, R. (ed.) (1995, Fifth International Colloquium on Ancient Mosaics, Part Two, Ann Arbor.

LIMC = Lexicon Iconographicum Mythologiae Classicae, 1992, Zürich y München.

NEGEV, A. (1995): «Petra Research», Qad 28 (110): $97-112$ (en hebreo).

OvadiaH, A. (1993): Mosaic Art in Ancient Synagogues in Israel from the $4^{\text {th }}$ to the $7^{\text {th }}$ Centuries, Tel Aviv.

- (1994): "Observations on the Mosaic Art in Ancient Synagogues", en La mosaïque gréco-romaine, Paris: 210-217, pls. CXXVIII-CXXXVI.

- (1995): «Art of the Ancient Synagogues in Israel», en URman, D.; Flesher, P. V. M. 1995, Ancient Synagogues, vol. 2, Leiden-New-York-Köln: 309-318.

PARRISH, D. (1980): "The Calendar Mosaic from Antioch: a New Interpretation of Its lllustration of the Months", en VI coloquio internacional sobre mosaico antiguo, PalenciaMérida, 1980: 383-389. 
PARRISH, C. (1984): Season Mosaics of Roman North Africa, Rome.

PERKINS, A. (1973): The Art of Dura-Europos, Oxford.

Piccirillo, M. (1993): The Mosaics of Jordan, Amman.

Qad $=$ Qadmoniot

RAHMANI, Y. (1996): "Representation of the Seasons on a Christian Lead Coffin from Nirim", 'Atiqot 28: 147-159.

RaHNER, H. (1963): Greek Myths and Christian Mysteries, New York.

$R B=$ Revue Biblique

Roussin, L. A. (1995): "East meets West: the mosaics of the villa of Ein Yael (Jerusalem)", en LING 1995: 31-42

- (1997): "The Zodiac in Synagogue Decoration", in D. R. Edwards, Archaeology and the Galilee. Texts and Contexts in the Graeco-Roman and Byzantine Periods, Atlanta: 83-96

SAller, S. J.; Bagatti, B. (1949): The Town of Nebo (Khirbet el-Mekhayyat) with a brief summary of other Christian monuments in Transjordan, Jerusalem.

SMITH, M. (1982): “Helios in Palestine", Eretz Israel 16:199*-214*.

STERN, H. (1981): «Les calendriers romains illustrés», en ANRW II: 431-475.

STERN, E. (ed) (1993): The New Encyclopedia of Archaeological Excavations in the Holy Land, Jerusalem.

Stone, 1. (1953): "The Zodiac Theme in Ancient Synagogues and in Hebrew Printed Books", en Studies in Bibliography and Booklore, vol. I: 3-13.

SUKENIK, E. L. (1932): The Ancient Synagogue of Beit Alpha, Jerusalem. - (1951): Bulletin of the L.M. Rabinowitz Fund 2: 6-24.

TALGam, R. (1998): "Mosaics in Israel in the Light of Recent Discoveris", Qad 31 (116): 74 89 (Hebrew).

TOMASEVIC, G. C. (1995): "Représentations symboliques du cosmos dans l'art figuratif et dans l'architecture", en LING 1955: 279-292.

VINCENT, H. (1922): “Une villa gréco-romaine à Beit Djebrin», RB 19: 259-281, PI. VIII-X.

VINCENT, L. H. y BENOIT, P. (1961): «Un sanctuaire dans la region de Jericho", RB 68: $161-177$ y pls. $V$-XXIII.

WeISS, Z.-NETZER, E. (1997): "The Hebrew University Excavations at Sepphoris", Qad 30 (113) (1997) 2-21 (en hebreo).

Weiss, Z.-TALgam, R. (1980): "The Dionysiac Mosaic Floor of Sepphoris", en VI Coloquio internacional sobre mosaico antiguo, Palencia-Mérida: 231-237.

WILLKINSON, J. (1978): "The Beit Alpha Synagogue Mosaic Towards an Interpretation», Journal of Jewish Art 5: 16-28. 